\title{
Why Soot is not Alike Soot: A Molecular/Nanostructural Approach to Low Temperature Soot Oxidation
}

\author{
Fabian Hagen, et al. [full author details at the end of the article]
}

Received: 25 March 2020 / Accepted: 29 July 2020 / Published online: 29 August 2020

(c) The Author(s) 2020

\begin{abstract}
Due to worldwide increasingly sharpened emission regulations, the development of Gasoline Direct Injection and Diesel Direct Injection engines not only aims at the reduction of the emission of nitrogen oxides but also at the reduction of particulate emissions. Regarding present regulations, both tasks can be achieved solely with the help of exhaust after treatment systems. For the reduction of the emission of particulates, Gasoline (GPF) and diesel Particulate Filters (DPF) offer a solution and their implementation is intensely promoted. Under optimal conditions particulates retained on particulate filters are continuously oxidized with the exhaust residual oxygen so that the particulate filter (PF) is regenerated possibly without any additional intervention into the engine operating parameters. The regeneration behavior of PF depends on the reaction rates of soot particles with oxidative reactants at exhaust gas temperatures. The reaction rates of soot particles from internal combustion engines (ICE) often are discussed in terms of order/disorder on the particle nanoscale, the concentration and kind of functional groups on the particle surfaces, and the content of (mostly polycyclic aromatic) hydrocarbons in the soot. In this work the reactivity of different kinds of soot (soot from flames, soot from ICE, carbon black) under oxidation conditions representative for PF regeneration is investigated. Soot reactivity is determined in dynamic Temperature Programmed Oxidation (TPO) experiments and the soot primary particle morphology and nanostructure is investigated by High-Resolution Transmission Electron Microscopy (HRTEM). An image analysis method based on known methods from the literature and improving some infirmities is used to evaluate morphology and nanostructural characteristics. From this, primary particle size distributions, length and separation distance distributions as well as tortuosities of fringes within the primary particle structures are obtained. Further, UV-visible spectroscopy and Raman scattering and other diagnostic techniques are used to study the properties connected to the reactivity of soot and to corroborate the experimental findings. It is found that nanostructural characteristics predominantly affect reactivity. Oxidation rates are derived from TPO and interpreted on a molecular basis from quantum chemistry calculations revealing a replication/activation oxidation mechanism.
\end{abstract}

Keywords Soot oxidation $\cdot$ Particulate filters $\cdot$ Soot nanostructure $\cdot$ Soot reactivity $\cdot$ Exhaust gas treatment 


\section{Introduction}

Due to the increasingly stringent emission regulations (The European Parliament and the Council of the European Union 2007), the development of Gasoline (GDI) and Diesel Direct Injection (DDI) engines aims at the reduction of particulate matter (PM) emissions by application of Gasoline (GPF) or Diesel Particulate Filters (DPF). Particulate filters (PF) trap soot particles present in the exhaust gases resulting in minimized PM emission. To allow for a continuous operation of PF, the captured soot is removed periodically by a regeneration procedure or continuously by oxidation with residual $\mathrm{O}_{2}$ in the exhaust gas (Fang and Lance 2004). The reaction rates of soot against oxidation by $\mathrm{O}_{2}$ determine the frequency and efficiency of this kind of PF-regeneration (Fang and Lance 2004; Bhardwaj et al. 2014). The regeneration behavior of PF depends on the reaction rates of soot particles with oxidative reactants at engine exhaust gas temperatures (573 K to approximately 1073 $\mathrm{K})$. Time scales of reactions of soot in oxidation determine the reactivity of soot and the reactivity of soot may be expressed through the reciprocal over-all rate coefficient of the oxidation reaction.

Although a contemporary topic of intensive research, oxidation reaction rates of soot at engine exhaust conditions are still barely predictable. Reaction rates of soot towards oxidation have been widely discussed under aspects ranging from physico-chemical properties via different morphological and nanostructural characteristics to its carbon nanostructure (Stanmore et al. 2001; Mühlbauer et al. 2016; Lu et al. 2012; Lapuerta et al. 2012).

Results reported from various investigations indicate diverse and sometimes conflicting influencing factors. Small soot primary particle sizes correlate with high reactivity (Stanmore et al. 2001; Lu et al. 2012; Lapuerta et al. 2012). Large specific surface area which correlates with small primary particle sizes is found to cause high soot reactivity (Fang and Lance 2004; Aarna and Suuberg 1997). The specific surface area (Fang and Lance 2004) as well as the pore structure within soot particles (Stanmore et al. 2001; Lu et al. 2012) are linked to the diffusive infiltration of oxidant into soot particles affecting also reactivity. Accessible active surface area rather than the overall surface area determines reactivity of soot particles (Aarna and Suuberg 1997; Neeft et al. 1997). Amongst the morphological characteristics of primary soot particles, their size distributions and fractal dimensions are indicators for reactivity. Sediako et al. (2017) observed changes in particle morphology during soot oxidation by real-time environmental TEM and demonstrated a correlation between soot aging and oxidation mode.

In addition the carbon nanostructure within primary soot particles is reported to affect considerably the reactivity towards oxidation. Soot primary particles consist of collocated packets of layered large polycyclic aromatic hydrocarbon molecules of different size with different functional edge-groups and distorted sites that can be assigned graphenelike characteristics (Pawlyta et al. 2015). Huang and Vander Wal (2016) demonstrated the dependence of the nanostructure of soot particles upon partial premixing and the associated changes in the gas-phase chemistry of ethylene-air Bunsen flames. The collocation of layered graphene-like structures measured by their length, separation distance and curvature as well as defects within the crystallite structure (Bhardwaj et al. 2014; Lapuerta et al. 2012; Vander Wal and Tomasek 2003; Pfau et al. 2018) altogether affect the reactivity of soot. Reactivity of soot, therefore, is a consequence of both agglomerate morphology and the nanostructure and chemical composition of primary particles (Pfau et al. 2018). The nanostructure determines the number density of $\mathrm{sp}^{2}$ and $\mathrm{sp}^{3}$-hybridized C-atoms and, therefore, the energy level of $\mathrm{C}$-atoms within these structures accessible for oxidation. The 
larger the number density of $\mathrm{sp}^{3}$-hybridized $\mathrm{C}$-atoms and the less organized the nanostructure of soot, the higher its reactivity and oxidation rate (Vander Wal and Tomasek 2003; Su et al. 2004; Knauer et al. 2009).

High-resolution transmission electron microscopy (HRTEM) provides information about the nanostructural properties such as distribution of length, distance and tortuosity of the graphene-like layers (Su et al. 2004; Knauer et al. 2009; Yehliu et al. 2011a; Palotas et al. 1996; Sadezky et al. 2005; Sharma et al. 2000; Vander Wal et al. 2004a, b). Although HRTEM is limited to ex-situ measurements and particles in the size range below about $10 \mathrm{~nm}$ as well as little contrast-forming particles are difficult to detect, it is the preferred method to investigate the carbon nanostructure of soot (Su et al. 2004; Yehliu et al. 2011a, b; Palotas et al. 1996; Sharma et al. 1999, 2000; Vander Wal et al. 2004a, b; Shim et al. 2000; Botero et al. 2016). Ultrafine particles with diameters in the $10 \mathrm{~nm}$ range or below and highly amorphous particles are emitted from GDI engines (Czerwinski et al. 2018; Bardi et al. 2019) and would not contribute to the fringe analysis. HRTEM images are analyzed qualitatively, manually, or with the help of computer-based image processing software (Vander Wal et al. 2004a, b; Shim et al. 2000; Sharma et al. 1999; Botero et al. 2016; Yehliu et al. 2011b). Large effort has been applied in recent years to improve quantitative analyses of HRTEM of soot, compare e.g. (Vander Wal et al. 2004a, b; Shim et al. 2000; Sharma et al. 1999; Botero et al. 2016; Yehliu et al. 2011b; Toth et al. 2013, 2015).

The objective of this work is to develop substantiated information about the oxidation of soot with molecular oxygen on a nanoscale/molecular level to identify the predominant parameters of soot governing its reactivity. As a remedy against some infirmities known from literature, a HRTEM image analysis method developed to perform a quantitative and reproducible analysis of the carbon nanostructure, has been applied to different soot and carbon black samples. Subsequently, the nanostructure determined by the image processing method is compared for the different soot and carbon black samples. Similar work has been performed by Pfau et al. (2018) comparing the nanostructure af carbon black and soot-inoil from gasoline and diesel engines

The results are further interpreted using data obtained for the reactivity of soot and carbon black in oxidation with oxygen derived from temperature programmed oxidation (TPO). Further, UV-visible spectroscopy and Raman Scattering and other diagnostic techniques are used to support the study of the reactivity of soot during oxidation. Soot samples are inspected at different burn-out ratio providing valuable information about the development of reactivity during particle burn-out and some evidence for the development of oxidation models. Results are interpreted with kinetic models and oxidation rate kinetics are derived from TPO and interpreted on a molecular basis from quantum chemistry calculations.

\section{Materials and Methods}

\subsection{Materials}

In this work a vast variety of soot particles has been investigated. Soot samples were generated using a Graphite Spark Discharge Generator (GFG-3000, Palas GmbH, Germany) at a voltage of $2500 \mathrm{~V}$ and a discharge frequency of $500 \mathrm{~Hz}$. The argon carrier gas flow was set

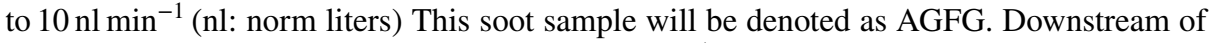
the aerosol generation, a nitrogen flow of $10 \mathrm{nl} \mathrm{min}^{-1}$ was used to dilute the aerosol before 
Table 1 Properties of the investigated soot and carbon black samples ordered by increasing reactivity

\begin{tabular}{|c|c|c|c|c|c|}
\hline Sample (abbreviation) & $\operatorname{BET}\left(\mathrm{m}^{2} \mathrm{~g}^{-1}\right)$ & $\mathrm{CMD}(\mathrm{nm})$ & $\mathrm{C} / \mathrm{H}(-)$ & $\mathrm{X}_{\mathrm{O}_{2}}(\mathrm{~mol} \%)$ & $\mathrm{T}_{\max }(\mathrm{K})$ \\
\hline Alfa $\operatorname{Aesar}^{\mathrm{TM}}(\mathrm{AC} 100)$ & 70 & 42 & 22 & 0.69 & 1063 \\
\hline Printex ${ }^{\circledR} 25(\mathrm{P} 25)$ & 46 & 54 & 19 & 0.00 & 1010 \\
\hline Printex ${ }^{\circledR} 45(\mathrm{P} 45)$ & 81 & 31 & 18 & 1.05 & 965 \\
\hline Spark discharge soot $\mathrm{N}_{2}$ (NGFG) & 426 & 5 & 10 & 5.14 & $963 / 796 / 570$ \\
\hline Printex ${ }^{\circledR} 90(\mathrm{P} 90)$ & 293 & 17 & 17 & 1.28 & 949 \\
\hline iso-Octane, 3 bar (i-OCT3) & 62 & 24 & 7 & 1.56 & 944 \\
\hline Printex ${ }^{\circledR} 85(\mathrm{P} 85)$ & 173 & 16 & 17 & 1.81 & 937 \\
\hline Diesel soot (C50_1200) & 409 & - & 7 & - & 935 \\
\hline Acetylene flame soot (ACFL) & 96 & 15 & 8 & 4.98 & 924 \\
\hline iso-Octane, 2 bar (i-OCT2) & 89 & 26 & 7 & 1.14 & 923 \\
\hline iso-Octane, 1 bar (i-OCT1) & 94 & 37 & 6 & 1.32 & 916 \\
\hline Spark discharge soot Ar (AGFG) & 679 & 3 & 4 & - & $911 / 796 / 570$ \\
\hline Diesel soot (C50_1600) & 453 & - & 7 & - & 906 \\
\hline GDI soot (A22) & - & 28 & - & - & $895 / 570$ \\
\hline GDI soot (A22_1) & - & 45 & - & - & $895 / 795$ \\
\hline GDI soot (A33) & - & 23 & - & - & 891 \\
\hline Diesel soot (C50_2200) & 284 & - & 6 & - & 786 \\
\hline
\end{tabular}

Values of $\mathrm{T}_{\max }$, the temperature of maximum oxidation rate during TPO, are derived from TPO profiles, see Sect. 2.2.1. Some soot samples exhibit multiple peaks in the TPO profiles indicated by multiple $\mathrm{T}_{\max }$ values

collecting it on filters. The carrier gas argon has been replaced by nitrogen at the same flow rate to generate a further soot sample (NGFG). Additional soot samples were prepared by collecting soot on quartz fiber filters downstream of a low pressure (200 mbar) flat premixed laminar acetylene/oxygen flame (equivalence ratio $\phi=2.7$ ) (ACFL) and flat premixed iso-octane/oxygen/argon flames $(\phi=2.3)$ at pressures of 1 bar, 2 bar and 3 bar (i-OCT1, i-OCT2, i-OCT3). Flame soot samples were Soxhlet-extracted to remove adsorbed polycyclic aromatic hydrocarbons (PAH). In addition, soot samples from a turbocharged 4 cylinder research GDI engine (2.0 liters) collected close to the manifold at medium (A22) and high (A33) engine load have been included. Sample A22_1 is obtained from the GDI engine operated with a modified injection pressure (87.5 bar compared to 100 bar for sample A22). Engine conditions are given in detail in Koch et al. (2020). The ICE soot was complemented by samples from a commercial Diesel Direct Injection engine at injection pressures of 2200 bar, 1600 bar and 1200 bar (C50_2200, C50_1600, C50_1200). Sampling procedure and engine description is delineated in Lindner et al. (2014). For comparison commercial carbon black samples were investigated. The carbon blacks examined are Printex ${ }^{\circledR} 25$ (P25), Printex ${ }^{\circledR} 45$ (P45), Printex ${ }^{\circledR} 85$ (P85) and Printex ${ }^{\circledR} 90$ (P90) (Orion Engineered Carbons, Luxembourg) manufactured by the furnace carbon black process and acetylene carbon black Alfa Aesar ${ }^{\mathrm{TM}}$ (ThermoFischer Scientific Inc., USA), 100\% compressed (AC100). The carbon black samples provide materials with a wide range of mean primary particle sizes, specific surface areas and reactivity, see Table 1. As commercial products they are easily available and, therefore, are ideally for the investigation presented here.

Table 1 summarizes some properties of the investigated soot and carbon black samples: The BET specific surface area (BET), the count median diameter (CMD) of the primary 
particle size distribution approximated by a log-normal distribution, the $\mathrm{C} / \mathrm{H}$ atomic ratio and the oxygen mole fraction $\mathrm{X}_{\mathrm{O}_{2}}$ determined by elemental analysis and the temperature of maximum reaction rate $\left(\mathrm{T}_{\max }\right)$ during TPO. $\mathrm{T}_{\max }$ is widely used to indicate the reactivity towards oxidation, where low temperatures are linked to high reactivity and vice versa, see following sections.

As can be noticed from Table 1, the properties of the investigated soot and carbon black samples are spread over a wide range in magnitude. The listed soot samples were chosen deliberately to harden or exclude correlations of the reactivity against oxidation with different morphological, chemical and nanostructural properties. Some correlations between properties, e.g. reactivity indicated by $\mathrm{T}_{\max }$, the temperature of maximum oxidation rate during TPO, with specific surface area and mean primary particle size, differ from those given in the literature, see GDI and carbon black soot samples. Equally well, e.g. the relationship between specific surface area and mean primary particle size differs from the expected one (the higher the specific surface area the lower the mean primary particle size), see the Printex ${ }^{\circledR}$ samples. On the other hand, some properties between different samples are similar, so that conflicting results can be explained by widening the spectrum of influencing factors and identifying those with highest weight.

The various applied analytical methods for the investigation of the soot samples, see Sect. 2.2, require varying sample amounts. Due to the different origin of the soot (commercial carbon black, soot from ICE, soot from flames), only varying quantities were available for the experiments. Therefore, not every method could be applied fully to the entity of soot samples, which particularly applies to the soot samples from ICE. However, due to the similarity with respect to measured morphological and nanostructural properties, these samples were withheld in the discussion for comparison.

The emission of soot from ICE depends significantly on operation conditions such as injection pressure, injection timing, multiple injection patterns, load etc., resulting in soot which is not alike soot when looking at some bulk properties. However, soot from ICE is similar to flame generated soot or carbon black with respect to morphological and nanostructural properties and, therefore, is alike these kinds of soot with respect to reactivity against oxidation. Vice versa, alike soot with respect to some bulk properties exhibits diverse nanostructure and reactivity. For the above reasons, the wide range of soot samples including soot from ICE was considered in the tests, though the application of the full diagnostic and analytic methods to all these samples was limited.

\subsection{Applied Methods}

The elemental analysis of the elements carbon, nitrogen and hydrogen was performed using a Vario Micro Cube elemental analyzer (Elementar Analysensysteme GmbH, Germany). The measurement system is equipped with thermal conductivity (TCD) and infrared (IR) detectors. The soot sample mass was $2.5 \mathrm{mg}$ for each measurement.

Specific surface areas were measured using a BELSORP-mini (BEL Japan Inc., Japan) volumetric adsorption measurement instrument with nitrogen physisorption at $77 \mathrm{~K}$. Prior to the measurements, the apparatus was calibrated using internal standards. Soot samples were outgassed in vacuum at $378.15 \mathrm{~K}$ before the measurements. The resulting isotherms were analyzed conforming to the latest IUPAC recommendations with respect to the BET surfaces.

UV-visible spectroscopy was performed with soot particle suspensions in N-methyl-pyrrolidone (NMP). Apicella et al. (2004) mention, that NMP is a suitable solvent to achieve stable 
suspensions of carbon-rich, solid materials. Sample preparation was carried out by mixing sample and solvent, followed by dispersing with an ultrasonic homogenizer (Bandelin, Sonoplus HD3200, Germany) for 10 minutes. The spectral response of the solvent NMP in the UV limits the visualization of the spectra to a region of 280-800 $\mathrm{nm}$. UV-visible spectra were measured in the absorbance mode on a Chirascan (Applied Photophysics, UK) spectrometer and the Cary $300 \mathrm{UV}$-visible spectrometer (Agilent, USA) using $1 \mathrm{~cm}$ quartz cuvettes. Each sample was measured four times, while the cuvette was refilled before each measurement.

\subsubsection{Oxidation Rates}

The oxidation rates of the soot samples were measured through temperature programmed oxidation (TPO) employing thermogravimetric analysis (TGA) (Koch et al. 2020; Hagen et al. 2020). Dynamic, non-isothermal measurements were performed with a TG 209 F1 Libra thermo balance (Netzsch Gerätebau GmbH, Germany) at a heating rate of $5 \mathrm{~K} \mathrm{~min}^{-1}$. The soot samples with a sample mass of $2 \pm 0.2 \mathrm{mg}$ were oxidized under an atmosphere consisting of $5 \% \mathrm{vol} \mathrm{O}_{2}$ and $95 \% \mathrm{vol} \mathrm{N}_{2}$ at atmospheric pressure. The thermo balance was temperature-calibrated with reference to the melting points of $\mathrm{In}, \mathrm{Sn}, \mathrm{Bi}, \mathrm{Zn}, \mathrm{Al}$ and $\mathrm{Ag}$. In addition to virgin soot, soot samples at different burn-out ratios (mostly 0\%, 20\%, 60\%, $80 \%, 90 \%$ ) have been investigated.

Complementary to the dynamic TPO-experiments, soot samples were also oxidized stepwise to mass losses of $20 \%, 60 \%, 80 \%$ and $90 \%$. During these experiments soot samples were heated up in the thermobalance under inert conditions $\left(\mathrm{N}_{2}\right)$ applying a heating rate of $200 \mathrm{~K} \mathrm{~min}^{-1}$. After attaining the reaction temperature of $1073 \mathrm{~K}$, soot samples were oxidized with a mixture of $5 \%$ by volume of $\mathrm{O}_{2}$ in $\mathrm{N}_{2}$ under isothermal conditions until the desired mass loss and cooled down under inert conditions. After each oxidation step part of the sample was examined with regard to the reactivity of the primary particles by TPO and by HRTEM analysis and the remaining sample was used for the subsequent oxidation step.

As far as reaction mechanisms based on elementary reactions are not available, the oxidation of soot may be described with the help of global over-all kinetic expressions. To deduce kinetic parameters for the oxidation of soot with excess of oxygen from the TPO profiles, a reacting-volume model of the form

$$
\frac{d m_{\text {soot }}}{d t}=-k_{o x}^{(1)} \cdot p_{O_{2}}^{m} \cdot N_{a c t}^{n}
$$

is applied, where $m_{\text {soot }}$ means the actual soot mass, $p_{\mathrm{O}_{2}}$ is the oxygen pressure and $N_{\text {act }}$ the number density of sites accessible for oxidation with the reaction order $\mathrm{m}$ and $\mathrm{n}$, respectively. $k_{o x}^{(1)}$ is the corresponding reaction rate coefficient. For $\mathrm{O}_{2}$ in excess, $p_{\mathrm{O}_{2}}$ can be regarded being constant and according to the reacting-volume model $N_{a c t}$ can be approximated assuming $N_{\text {act }} \propto m_{\text {soot }}$. This results in

$$
\frac{d m_{\text {soot }}}{d t}=-k_{\text {ox }}^{(2)} \cdot m_{\text {soot }}^{n}
$$

Introducing $\alpha=m_{\text {soot }} / m_{0 \text { soot }}$ gives

$$
\frac{d \alpha}{d t}=-k_{o x}^{(3)} \cdot \alpha^{n}
$$

When performing TPO experiments with a constant heating rate $\beta=\frac{d T}{d t}$ the rate equation can be rewritten as 
Fig. 1 Calculated TPO-profiles according to Eq. 4 at different reaction order $\mathrm{n}$ using $k_{0 x}^{(4)}=4.0 \cdot 10^{6} \mathrm{~K}^{-1}$ and $E_{a}=100 \mathrm{~kJ} \mathrm{~mol}^{-1}$

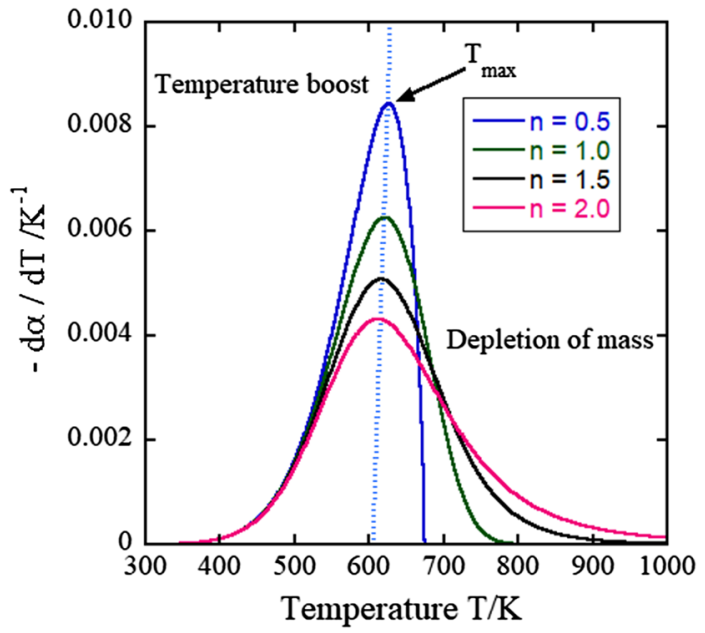

$$
\frac{d \alpha}{d T}=-k_{o x}^{(4)} \cdot \alpha^{n}=k_{0 x}^{(4)} \cdot \exp \left[-\frac{E_{a}}{R \cdot T}\right] \cdot \alpha^{n} .
$$

The rate coefficient $k_{o x}^{(4)}$ contains the heating rate and in case of $n \neq 1$ the initial mass $m_{0 \text { soot }}$. Therefore, all TPO experiments are performed with a constant initial mass of $2 \mathrm{mg}$ and a constant heating rate of $5 \mathrm{~K} \mathrm{~min}^{-1}$ to compare rate coefficients. The temperature dependency of the rate coefficient is expressed with the help of a simple Arrhenius approach $k_{o x}^{(4)}=k_{0 x}^{(4)} \cdot \exp \left[-\frac{E_{a}}{R \cdot T}\right]$ where $E_{a}$ is the apparent activation energy of the over-all reaction. The reactivity of soot may be expressed through the reciprocal rate coefficient $k_{o x}^{(4)}$

The three-parameter rate coefficient can be obtained by numerical integration of the model equation Eq. 4 and fitting it to measured TPO profiles with the help of non-linear regression, e.g. via the method of Levenberg-Marquardt. As alternative the easily to measure temperature $\mathrm{T}_{\max }$ at the maximum change $\frac{d \alpha}{d T}$ can be used to describe reactivity. Figure 1 exhibits TPO-profiles computed for $k_{0}^{(4)}=4.0 \cdot 10^{6} \mathrm{~K}^{-1}$ and $E_{a}=100 \mathrm{~kJ} \mathrm{~mol}^{-1}$. The left branch of the TPO-profiles until the maximum is determined by the temperature dependency of the oxidation rate while the right branch of the rate is limited by the depletion of the soot mass. $\mathrm{T}_{\max }$, the temperature of maximum oxidation rate during TPO (indicated by the broken line), is correlated approximately linearly to the apparent activation energy meaning that low $\mathrm{T}_{\max }$ indicates high reactivity and vice versa (e.g. $T_{\max }=6.0 \cdot E_{a}+30$ for $k_{o x}^{(4)}=4.0 \cdot 10^{6} \mathrm{~K}^{-1}, n=1$ and $E_{a}$ in $\left.\mathrm{kJ} \cdot \mathrm{mol}^{-1}\right)$.

\subsubsection{Raman Microscopy}

The Raman spectra of soot samples were obtained using a Renishaw inVia Raman Microscope with Fiber Optic Probe (FOP) equipped with a Nd:YAG laser (532 nm, laser power $150 \mathrm{~mW}$ ). Spectra were recorded from 50 to $2000 \mathrm{~cm}^{-1}$. For the detection a grid with $1800 \mathrm{~mm}^{-1}$ spacing and a CCD detector with an objective of 100 fold magnification was employed.

Raman spectra of soot can be characterized by a 5-peaks structure (Hagen et al. 2020; Ferrari and Robertson 2000) containing a G-peak at about $1580 \mathrm{~cm}^{-1}$ (graphite band, G), 


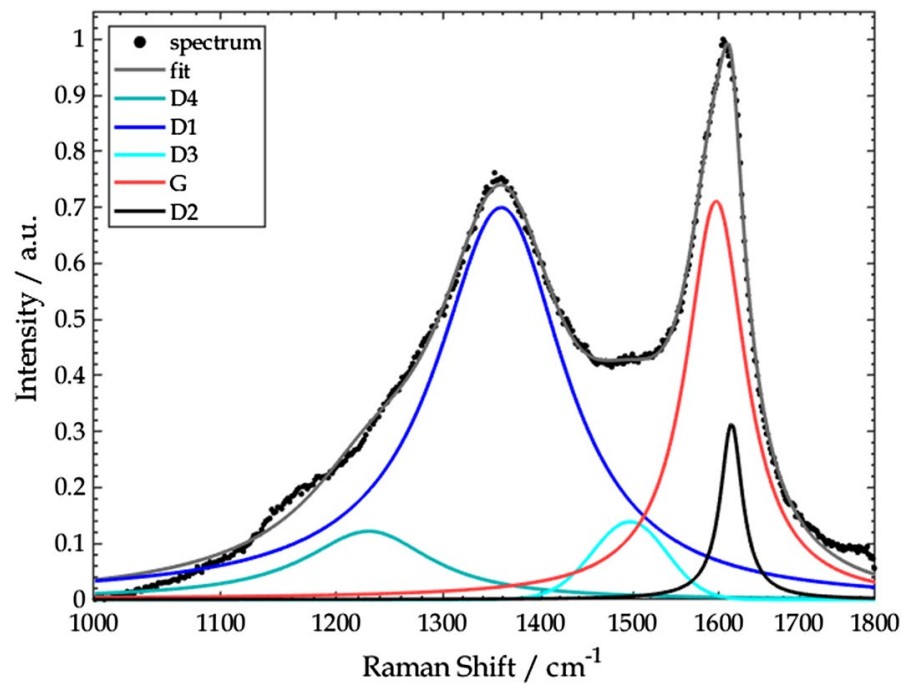

Fig. 2 Raman spectrum of the i-OCT3 sample and 5 band fitting procedure for identification of D- and G-bands. Symbols represent measured spectrum, gray line the fit $\left(R^{2}=0.9947\right.$ with $n=482$ data points)

see Fig. 2. This band is attributed to an ideal graphitic lattice and caused by the relative motion of $\mathrm{sp}^{2}$ carbon atoms $\left(\mathrm{E}_{2 \mathrm{~g}}\right.$-symmetry). The D-peak at about $1355 \mathrm{~cm}^{-1}$ is a breathing mode of the carbons in six-membered rings $\left(\mathrm{A}_{1 \mathrm{~g}}\right.$-symmetry). This mode becomes active only in presence of disorder (defect or disordered bands, D1). A peak at about $1620 \mathrm{~cm}^{-1}$ refers to disordered graphitic structures (D2, $\mathrm{E}_{2 \mathrm{~g}}$-symmetry), whereas the peak at about $1500 \mathrm{~cm}^{-1}$ (D3) is attributed to amorphous carbon. Finally the peak at about $1200 \mathrm{~cm}^{-1}$ (D4, $\mathrm{A}_{1 \mathrm{~g}}$-symmetry) is attributed to $\mathrm{sp}^{2}$ and $\mathrm{sp}^{3}$ carbon atoms not necessarily in six-membered rings. To reproduce the spectra a 5-band-fitting procedure according to Sadezky et al. (2005), Ferrari and Robertson (2000) has been applied, which is demonstrated in Fig. 2. The figure displays the measured spectrum (symbols) and the intensity of the D1- to D4 and G-peaks as well as the fitted spectrum (gray line). This allows the estimation of the relative intensities of D- and G-bands providing qualitative information about the abundance of graphitic ordered structures and disordered regions and the content of amorphous carbon. High values of the intensity ratio $\mathrm{I}_{\mathrm{D} 1} / \mathrm{I}_{\mathrm{G}}$ indicate predominance of low ordered graphene-like structures with small extension whereas low values suggest well ordered, graphitic graphene-like structures of large extension.

\subsubsection{HRTEM Image Preparation and Processing}

In preparation of HRTEM recordings, soot samples were mixed with ultra-pure water, stirred by ultrasound and dispersed onto a carbon-coated TEM copper grid. HRTEM images were acquired using a Philips CM200 transmission electron microscope (ThermoFischer Scientific Inc., USA), operated at $200 \mathrm{kV}$ and a magnification of 380.000 resulting in a spatial resolution of $0.0283 \mathrm{~nm} \mathrm{px}^{-1}$.

Size distributions of primary soot particles have been determined from HRTEM images of soot particle aggregates applying a MATLAB-procedure, the single steps of which are illustrated in Fig. 3. After reading the TEM images, appropriate scaling and selection of a 


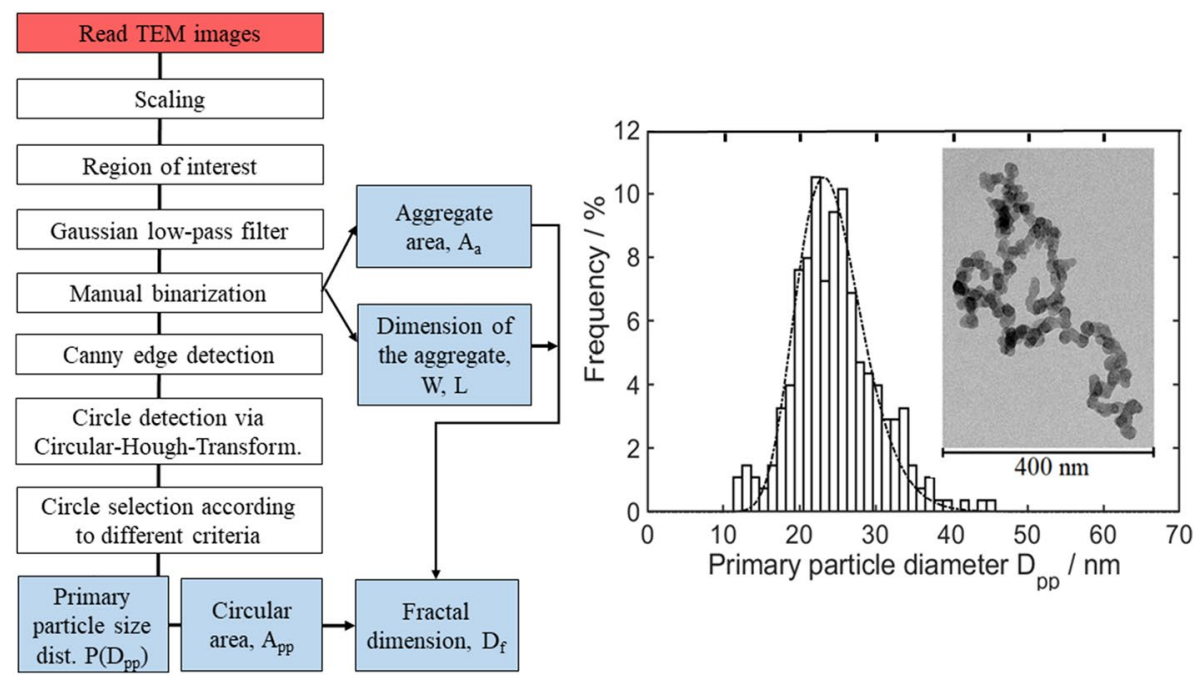

Fig. 3 Procedure for evaluation of primary particle size distributions from HRTM images and example from i-OCT3 soot. Measured size distribution (right diagram) is approximated by a log-normal distribution with $\mathrm{CMD}=24 \mathrm{~nm}$ and $\sigma_{g}=1.2$. HRTEM of an exemplary aggregate is also given

region of interest a Gaussian low-pass filter is applied, to remove background noise. These steps are followed by binarization as well as edge enhancement and a Hough transformation to detect circular objects.

The Hough transformation leads to the detection of an excessive number of circular objects not all being primary particles. Therefore, different operations are applied to extract circles representing actual particles with their accurate diameter. The outlines of detected circles are compared to edge structures extracted from the original image. Overlapping circles are then ranked and deleted according to their congruity with those edge structures, leaving only well-fitting circles. At last, size distributions of the detected primary soot particles and fractal dimensions $\mathrm{D}_{\mathrm{f}}$ are calculated. The fractal dimension according to the minimum bounding rectange (MBR) method is given by

$$
D_{f}=d\left(\ln \left[\left(\frac{A_{a}}{A_{p p}}\right)^{\alpha}\right]\right) / d\left(\ln \frac{\sqrt{L \cdot W}}{r_{p p}}\right),
$$

with the circular area $\mathrm{A}_{\mathrm{pp}}$, the aggregate area $\mathrm{A}_{\mathrm{a}}$ and the width $\mathrm{W}$ and length $\mathrm{L}$ of the aggregate. The exponent $\alpha$ is taken from Köylü et al. (1995), $\alpha=1.09$. Size distributions are based on the evaluation of about five exposures and 100-500 primary particles each. The procedure has been tested with synthetically generated size distributions before application.

The essential steps of HRTEM image processing to evaluate the primary particle nanostructures are filtering in the Fourier space, binarization, skeletonizing elements, post-processing of the skeletons and analysis of fringe length, tortuosity and separation distance of the fringes (Shim et al. 2000; Sharma et al. 1999; Yehliu et al. 2011b). For binarization the choice of a suitable, global threshold (TH) still represents an unsatisfied challenge. While the evaluation of fringe length and tortuosity is well established, the calculation of the separation distance still contains uncertainties and difficulties. 

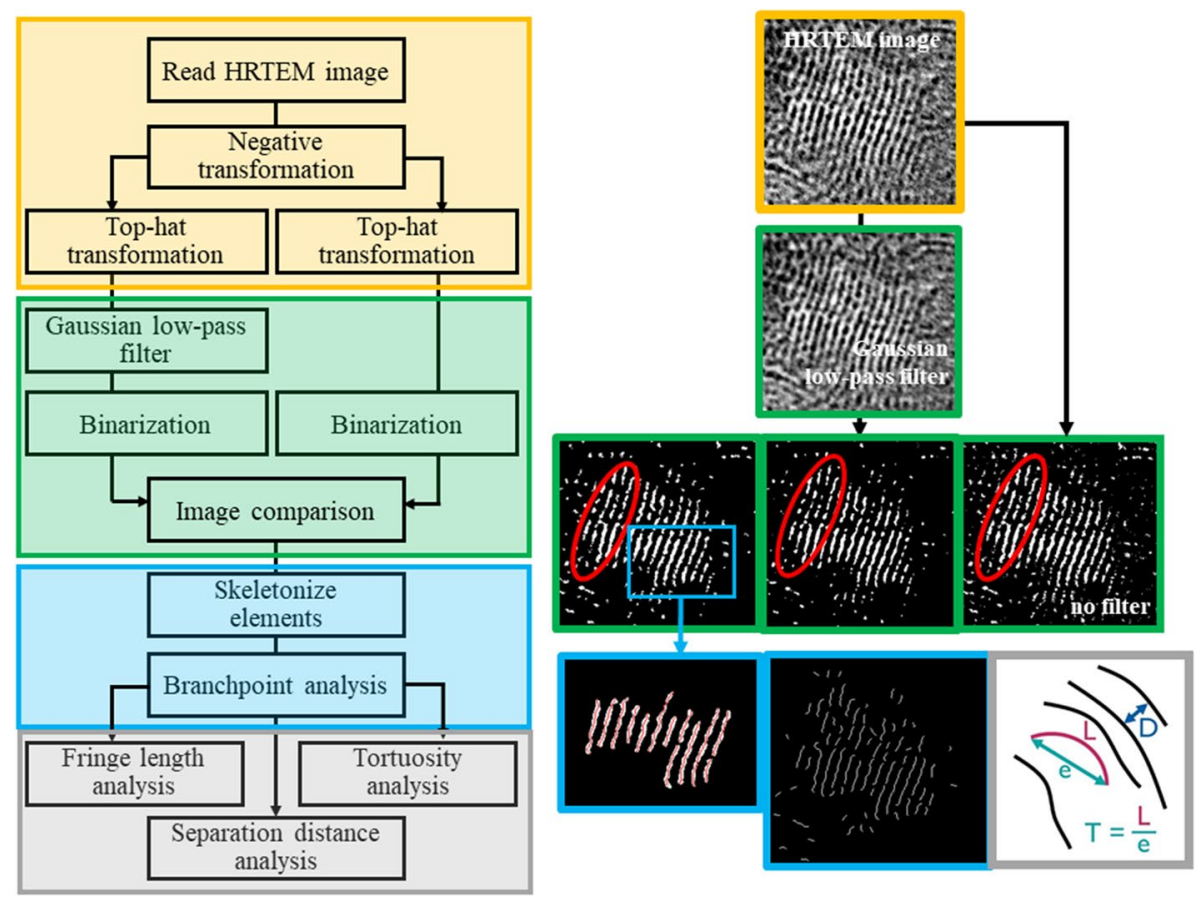

Fig. 4 Procedure for evaluation of the nanostructure of primary particles

The single steps of the procedure used in this work are depicted in Fig. 4, see also Koch et al. (2020). The single computing steps are given in the left part of the figure and illustrated with the help of corresponding HRTEM images (right part). The imported 16-bit HRTEM images are saved as gray scale matrices. The images are inverted, top-hat transformed and their spatial resolution is calculated (yellow framed rectangles). In order to reduce the background noise resulting from optical distortion of the HRTEM images, the use of a Gaussian low-pass filter is an established method (Botero et al. 2016; Gonzalez and Woods 2008). In addition to removing small background structures, larger structures are reduced in size (Sharma et al. 1999). This leads to a loss of carbon fringe layers or a separation of structures. To counteract this effect, an image comparison is implemented in the algorithm. By comparing filtered and unfiltered images only structures present in the filtered image are kept but then replaced by the original unfiltered structure (green framed rectangles). As a result, background noise is significantly reduced while fringes maintain shape and size.

Binarization separates pixels into two different categories due to their intensity. The use of top-hat transformation is an established method to prepare an image for binarization. Differences in exposure within an image make a global threshold (TH) unfit for this task. According to a $\mathrm{TH}$, the intensity $\mathrm{I}=\{0,1\}$ ( $\mathrm{I}=1$ foreground, $\mathrm{I}=0$ background) is assigned to every pixel during binarization. The determination of a suitable TH is considered as crucial for image processing (Yehliu et al. 2011b; Gonzalez and Woods 2008; Galvez et al. 2002; Serra 1989). An ideal TH is achieved when pixel intensities show a bimodal distribution. Then, the $\mathrm{TH}$ value is equal to the local minimum 
in between the two maxima of the distribution. In HRTEM images, these modes would represent graphene-like structures and background, respectively. The intensity distributions of HRTEM images, however, are unimodal.

Applying the well-known Otsu threshold method (Jähne 2002) to the unimodal intensity distributions resulting from HRTEM images of soot primary particles, no suitable TH could be found. Therefore, a method was developed in this study, using a TH value that causes a minimal alteration of the graphene-like structures when changing its value. For this, the number of pixels per object has been calculated versus the value of the TH. The resulting histograms were fitted by a two parameter $\gamma$-function. The obtained functions exhibit regions in the parameter space (shape parameter and scale parameter) where the number of pixels changes only little with changing $\mathrm{TH}$ value. This transition region characterizes an ideal $\mathrm{TH}$ value for binarization where fringes are optimal separated from background pixels. As part of this development 215 HRTEM images have been analyzed. Only 19 of them $(\approx 8 \%)$ did not result in reasonable TH values. Further testing with the use of a different transmission electron microscope (FEI TITAN ${ }^{3}$ (80-300) (ThermoFischer Scientific Inc., USA), at $300 \mathrm{kV}$ ) also confirmed the method.

Skeletonizing the elements reduces all objects to lines with a width of one pixel. This prepares the image for calculating length L, Euclidian end point distance e and, hence, tortuosity $T=L / e$ of fringes. In this study, the objects are skeletonized by a ZhangSuen algorithm (Zhang and Suen 1984). Subsequently, a number is assigned to every object. Branches within the skeletonized structures, which are joined by branch point (BPs) originate from applying the skeletonization algorithm. The BP analysis aims at creating a continuous main structure by deleting branches not belonging to this main graphene-like structure. For this, Yehliu et al. (2011b) use a morphological opening and closing method. This method leads to an incomplete removal of branches of the carbon nanostructures investigated in this study. Therefore, each BP is analyzed individually using a similar procedure as introduced by Shim et al. (2000) as well as Sharma et al. (1999), (blue framed rectangles).

The fringe length results from counting the pixels of a structure while pixels are assigned different lengths according to their connection to neighboring pixels. A straight link between two pixels results in a length of $\mathrm{L}=1 \mathrm{px}$ while a diagonal connection is equal to the length of $\mathrm{L}=\sqrt{2} \mathrm{px}$. Tortuosity $\mathrm{T}$ describes the ratio of fringe length and Euclidian distance and, hence, the curvature of fringes. The separation distance D, on the other hand, is used to indicate the short-range order of fringes, see Fig. 4, (gray framed rectangles). The algorithm developed in this study allows an automated determination of both structural parameters. Prior to analyzing the nanostructure of soot and carbon blacks the developed image processing procedure programmed also in MATLAB has been validated by analyzing manually created, characteristic reference structures. This led to a maximum deviation of $3 \%$ concerning the length of the detected structures. For evaluation of the nanostructure 20 to 50 soot primary particles from different exposures and up to 5000 fringes were analyzed.

The length L, spacing D and tortuosity $\mathrm{T}$ of the fringes reflect a relationship to the corresponding properties of the graphene-like layers in the primary soot particles, so that "fringe" and "graphene-like layer" are used synonymously in the following. It should also be noted, that ultrafine particles with sizes in the $10 \mathrm{~nm}$ range and below and particularly amorphous particles emitted from GDI engines (Czerwinski et al. 2018; Bardi et al. 2019) are hardly accessible for this kind of analysis. 


\subsubsection{Quantum Chemistry Calculations}

For interpretation of the oxidation rates obtained from TPO-measurements quantumchemistry estimations have been performed. Applying these methods, calculations have to be restricted to comparatively small molecules to obtain reliable results. Therefore, model molecules which represent carbon structures in soot primary particles are used for this kind of calculations, see e.g. Sendt and Haynes (2011), Edwards et al. (2013, 2014).

Soot primary particles are built up of layered graphene-like structures consisting of large polycyclic aromatic hydrocarbons, partially equipped with functional groups and aliphatic side chains. Particularly in the state of incipient soot, smaller structures are linked via aliphatic bridges, see e.g. D'Anna (2009). The primary attack of $\mathrm{O}_{2}$ at temperatures of about $900 \mathrm{~K}$ occurs at aliphatic side chains or aliphatic bridges rather than at aromatic C-H-sites. According to Mehl et al. (2011), Zhang and McKinnon (1995), the respective rate coefficients differ by more than one order of magnitude. It is then likely, that aliphatic side chains and aliphatic bridges are stripped from the polycyclic aromatic structures first and the much slower activation of the remaining polycyclic aromatic structures constitutes the rate limiting step. Therefore, and because the amount of carbon fixed in these side chains and aliphatic bridges is low compared to that contained in the graphene-like structures, the polycyclic aromatic hydrocarbon pyrene has been used as a model molecule for graphene-like layers in soot primary particles in this work. The estimated rate coefficients presented in Sect. 3.4, therefore, are limited to activation/degradation reactions of this polycyclic structure. The hydrogen content of the investigated soot samples, which is even considerable for the soot sample with the lowest reactivity (AC100, see Table 1), is less compared to pyrene. However, considering the large extension of the polycyclic aromatic structures in the soot primary particles, the decrease of the hydrogen content with increasing size of the structures and the focus on the activation/degradation reactions of these structures, the choice of pyrene as a model molecule is justified.

The reactions of pyrene with molecular oxygen are investigated for developing kinetic models and oxidation rate kinetics. To determine the molecular properties of reactants, transition states and products of the different species occurring in the pyrene/ $\mathrm{O}_{2}$ system, the Gaussian 03/09 (Frisch et al. 2016) and the Gaussian-4 (G4) (Curtiss et al. 2007) program suites have been employed. The hybrid density functional method DFT (B3LYP), which combines the three parameter Becke exchange functional B3 with the Lee-Yang-Parr nonlocal correlation functional (LYP), with a double polarized set, 6-311G(d,p), is used to optimize geometries (Becke 1993; Lee et al. 1988; Montgomery et al. 1994). The use of DFT (B3LYP) is affordable and permits handling of large molecules at low computational costs. This method, when combined with isodesmic reactions, delivers good accuracy for thermodynamic data. B3LYP/6-311G(d,p) is chosen because it is reported to yield accurate geometry and reasonable energies and vibration frequencies at reasonable computational expense (Durant 1996; Andino et al. 1996). B3LYP has been validated previously by comparing results with higher level methods and its application for large molecules and radicals has produced reasonable results (Sebbar et al. 2008, 2015, 2011). Only transition state structures differ sometimes from other methods due to the differences in structures calculated by B3LYP.

The reaction rate coefficients for the primary reactions of pyrene with oxygen were calculated and compared with data from literature (Manion et al. 2015) when available. 

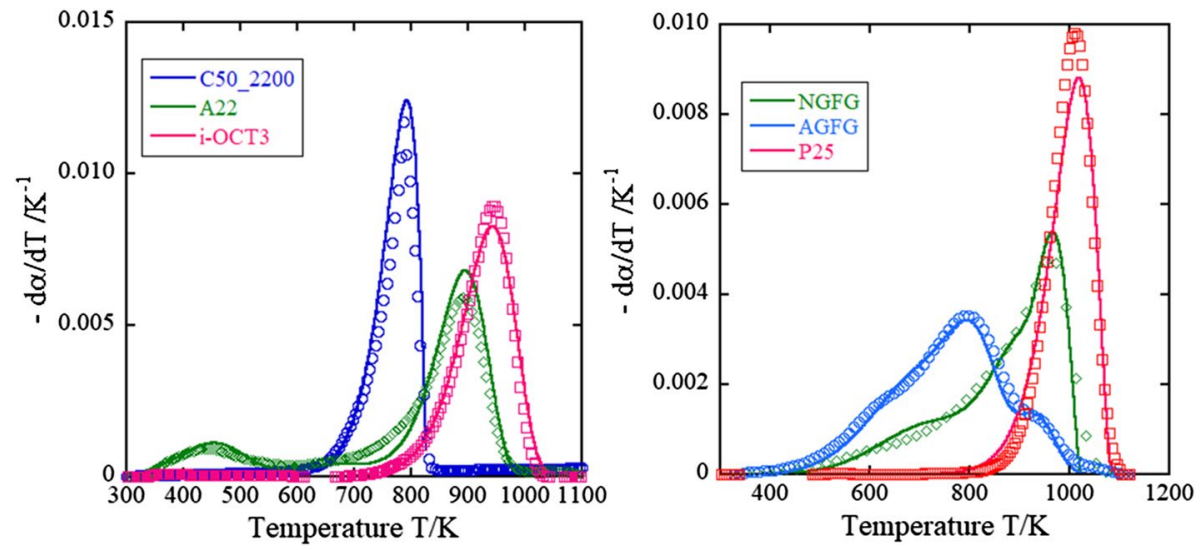

Fig. 5 TPO profiles of soot samples from Table 1, experimental results (symbols), calculated profiles (solid lines) derived from Eq. 4 and the fitting procedure introduced in Sect. 2.2.1 using the kinetic parameters given in Table 2

Kinetic parameters are determined as a function of temperature from the calculated thermochemical parameters using chemical activation analysis. Kinetic parameters are obtained from canonical transition state theory (TST) calculations.

\section{Results and Discussion}

\subsection{TPO-Results}

TPO-profiles for a subset of soot samples from Table 1 are given in Fig. 5. The figure contains the experimental results (symbols) and the calculated profiles derived from Eq. 4 and the fitting procedure introduced in Sect. 2.2.1 (solid lines) using the kinetic parameters given in Table 2. In Table $2 \mathrm{X}_{\mathrm{i}}$ means the mass fraction of the different soot types in the samples (NGFG, AGFG). The calculated values and the given digits represent the 95\% confidence interval from regression. As can be extracted from Fig. 5 and Table 2, oxidation rates of the soot and carbon black samples are spread over a wide range of $\mathrm{T}_{\max }$. The apparent activation energies cover a range from $\approx 95$ to $\approx 175 \mathrm{~kJ} \mathrm{~mol}^{-1}$ except for a low temperature peak appearing at about $570 \mathrm{~K}$ for NGFG and AGFG. Similar values for the over-all activation energies $\left(\approx 150 \mathrm{~kJ} \mathrm{~mol}^{-1}\right)$ of the ICE soot samples (C50_1200, C50_1600, C50_2200, A22) are reported in Zöllner et al. (2017). The A22 soot sample exhibits a low temperature peak at about $430 \mathrm{~K}$ (also present in the TPO of ACFL) which can be identified as evolution of volatiles by oxidizing the samples after heating them up under inert atmosphere up to about $800 \mathrm{~K}$. The spark discharge generated soot samples show three peaks in the TPO profiles at about $570 \mathrm{~K}, 790 \mathrm{~K}$ and $910 \mathrm{~K}$. The estimation of kinetic parameters works best when treating these samples as consisting of three independent kinds of soot, denoted as $\mathrm{AGFG}^{(1)}, \mathrm{AGFG}^{(2)}$ and $\mathrm{AGFG}^{(3)}$ and same for NGFG (Hagen et al. 2020). The A22 sample suggestively also exhibits the peak at $570 \mathrm{~K}$.

Treating soot samples such as AGFG or NGFG as consisting of three independent soot types raises the hypothesis that different reactive parts of primary particles in the soot aggregates are oxidized independently and the oxidation rate is a linear 
Table 2 Kinetic parameters according to Eq. 4 estimated using least squares minimization for soot samples from Table 1
Fig. 6 Experimental TPO profile of the soot sample A22_1 (red symbols) and calculated profile (red solid line) using a linear combination of the TPO profiles of A22 and AGFG

\begin{tabular}{|c|c|c|c|c|c|}
\hline Sample & $k_{0 \text { ox }}^{(4)}\left(\mathrm{K}^{-1}\right)$ & $\mathrm{E}_{\mathrm{a}}\left(\mathrm{kJ} \mathrm{mol}^{-1}\right)$ & $\mathrm{n}(-)$ & $\mathrm{X}_{\mathrm{i}}(\operatorname{mass} \%)$ & $\mathrm{T}_{\max }(\mathrm{K})$ \\
\hline $\mathrm{AC} 100$ & $7.2 \cdot 10^{6}$ & 173.0 & 1.0 & 100 & 1063 \\
\hline $\mathrm{P} 25$ & $4.5 \cdot 10^{6}$ & 160.0 & 1.0 & 100 & 1010 \\
\hline $\mathrm{NGFG}^{(3)}$ & $5.5 \cdot 10^{6}$ & 152.1 & 1.0 & 60.4 & 963 \\
\hline $\mathrm{NGFG}^{(2)}$ & $3.8 \cdot 10^{4}$ & 96.4 & 0.95 & 20.8 & 796 \\
\hline $\mathrm{NGFG}^{(1)}$ & 19.5 & 39.9 & 1.25 & 18.8 & 570 \\
\hline i-OCT3 & $4.2 \cdot 10^{6}$ & 150.0 & 1.0 & 100 & 944 \\
\hline P85 & $4.25 \cdot 10^{6}$ & 149.0 & 0.75 & 100 & 937 \\
\hline C50_1200 & $1.0 \cdot 10^{7}$ & 158.0 & 0.6 & 100 & 935 \\
\hline ACFL & $4.2 \cdot 10^{6}$ & 143.0 & 1.0 & 100 & 924 \\
\hline C50_1600 & $1.0 \cdot 10^{7}$ & 155.0 & 0.6 & 100 & 906 \\
\hline A22 & $4.2 \cdot 10^{6}$ & 142.0 & 1.2 & 100 & 895 \\
\hline $\mathrm{AGFG}^{(2)}$ & $3.8 \cdot 10^{4}$ & 96.4 & 1.2 & 48.0 & 796 \\
\hline $\mathrm{AGFG}^{(3)}$ & $5.5 \cdot 10^{6}$ & 152.1 & 1.0 & 15.0 & 911 \\
\hline $\mathrm{AGFG}^{(1)}$ & 19.5 & 39.9 & 1.2 & 38.0 & 570 \\
\hline C50_2200 & $4.5 \cdot 10^{6}$ & 125.0 & 0.6 & 100 & 786 \\
\hline
\end{tabular}

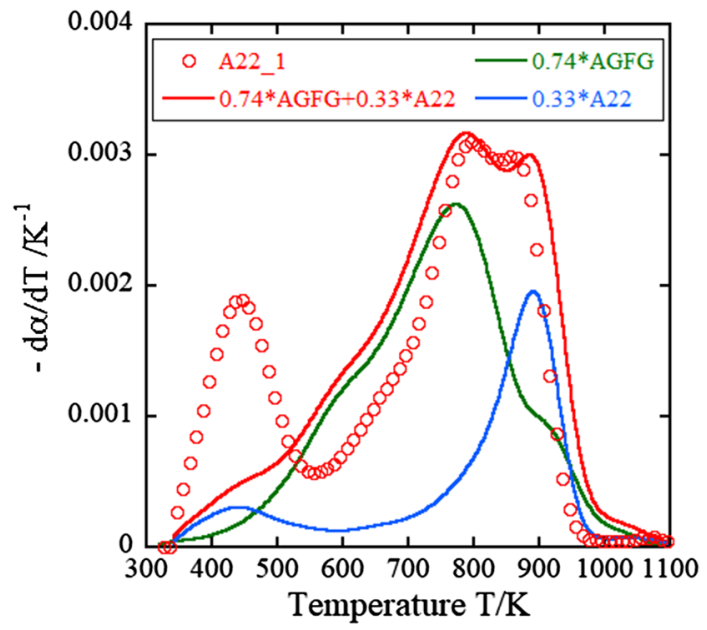

combination of the oxidation rates of the different soot types. This can be verified by the oxidation of soot sample A22_1 illustrated in Fig. 6 which contains the experimental oxidation rates of the sample (red symbols). The experimental TPO profile contains two major peaks at about $790 \mathrm{~K}$ and $890 \mathrm{~K}$ and includes features also exhibited by those of A22 and the most prominent peak of AGFG. The TPO profile calculated by a linear combination of these two TPO profiles $(0.74 *$ AGFG (green line) $+0.33 *$ A22 (blue line)) is indicated by the red solid line. The low temperature peak at about $450 \mathrm{~K}$ which represents the evolution of volatiles is excluded in the combination.

From the TPO experiments and the properties of the soot samples given in Table 1 no clear basic causes for the differences in reactivity are obvious. Comparatively small 
soot primary particle sizes are not well correlated with high reactivity in all samples, compare e.g. P45 with a CMD of $31 \mathrm{~nm}$ with A22 with a CMD of $28 \mathrm{~nm}$ and a difference in $\mathrm{T}_{\max }$ of about $70 \mathrm{~K}$. Similarly, large specific surface areas which correlate with small primary particle sizes cause different reactivity, compare e.g. NGFG with a BET surface of about $425 \mathrm{~m}^{2} \mathrm{~g}^{-1}$ and AGFG with about $680 \mathrm{~m}^{2} \mathrm{~g}^{-1}$ and a difference in $\mathrm{T}_{\max }$ for the most prominent TPO peak of about $160 \mathrm{~K}$. Also the content of volatiles present e.g. in the samples A22, A22_1 and ACFL obviously does not lead to comparable reactivity. If the oxygen content in the soot samples indicates the presence of functional groups at the surface of soot particles, also no clear correlation is found between reactivity and functional groups. Soot samples with alike bulk properties, e.g. P25, i-OCT1, A22 with a CMD of $\approx 30 \mathrm{~nm}$ or NGFG, C50_1200, C50_1600 with a BET of about $420 \mathrm{~m}^{2} \mathrm{~g}^{-2}$ are unalike with respect to reactivity (widely varying $\mathrm{T}_{\max }$, temperature of maximum oxidation rate during TPO). Vice versa, soot samples with alike reactivity, e.g. P90, i-OCT3, P85, C50_1200 with $\mathrm{T}_{\max } \approx 940 \mathrm{~K}$ are unalike with respect to bulk properties such as CMD or BET. Therefore, the basic causes for the dependency of reactivity on soot properties as stressed e.g. in Fang and Lance (2004), Stanmore et al. (2001), Lu et al. (2012), Lapuerta et al. (2012), Aarna and Suuberg (1997), Neeft et al. (1997) have to be extended to morphological and nanostructural aspects of the soot primary particles.

\subsection{Morphology and Nanostructures of Soot Primary Particles}

Primary particle size distributions of some soot samples are given in Fig. 7. The size distributions all resemble logarithmic normal size distributions which are also indicated in the diagrams (dashed lines). The mean particle sizes differ for the single samples, whereas the variances and fractal dimensions are similar. Similar size distributions are obtained for other soot samples listed in Table 1. As discussed in the previous section, no clear correlation between mean particle size and reactivity expressed via $\mathrm{T}_{\max }$ is observable from the size distributions.

In contrast to this, the distribution of fringe lengths and separation distances in the primary particles exhibit a clear correlation to $\mathrm{T}_{\max }$. The lower $\mathrm{T}_{\max }$ (the higher the reactivity), the smaller the fringe lengths and the wider the distribution of the fringe separation distance, see Figs. 8 and 9. Small fringe lengths are correlated to wide distributions of the separation distance and vice versa. For the most reactive soot sample (AGFG) fringe lengths range up to $3 \mathrm{~nm}$ and the separation distances range up to $0.6 \mathrm{~nm}$. The fringe length distribution for the least reactive soot sample (AC100) ranges up to higher than $7 \mathrm{~nm}$ with small separation distances (up to $0.45 \mathrm{~nm}$ ) and a much narrower distribution of those distances. For comparison: The extension of a $\mathrm{C}_{6}$-unit in graphite is $0.380 \mathrm{~nm}$ and the separation distance of the graphene layers in graphite amounts to $0.335 \mathrm{~nm}$.

The shape of the determined fringe length frequency distributions corresponds well with findings of other studies (Pfau et al. 2018; Yehliu et al. 2011a, b; Palotas et al. 1996; Rinkenburger et al. 2017). The fringe length distributions appear as approximately resembling Poisson-distributions or exponential distributions. These distributions are one-parameter distributions and, therefore, the mean fringe length seems to be sufficient for characterizing the distributions. The mean fringe lengths quantified in this study $\left[0.45 \mathrm{~nm}<\mathrm{L}_{\mathrm{f}}<0.7 \mathrm{~nm}\right.$, compare e.g. $\approx 0.9 \mathrm{~nm}$ (Pfau et al. 2018)] are slightly smaller than those calculated in the literature. This is most likely due to the comparatively high frequency of short structures $(<0.5 \mathrm{~nm})$. Particularly short structures are reconstructed in the algorithm due to the newly introduced image comparing procedure. Another reason for this 


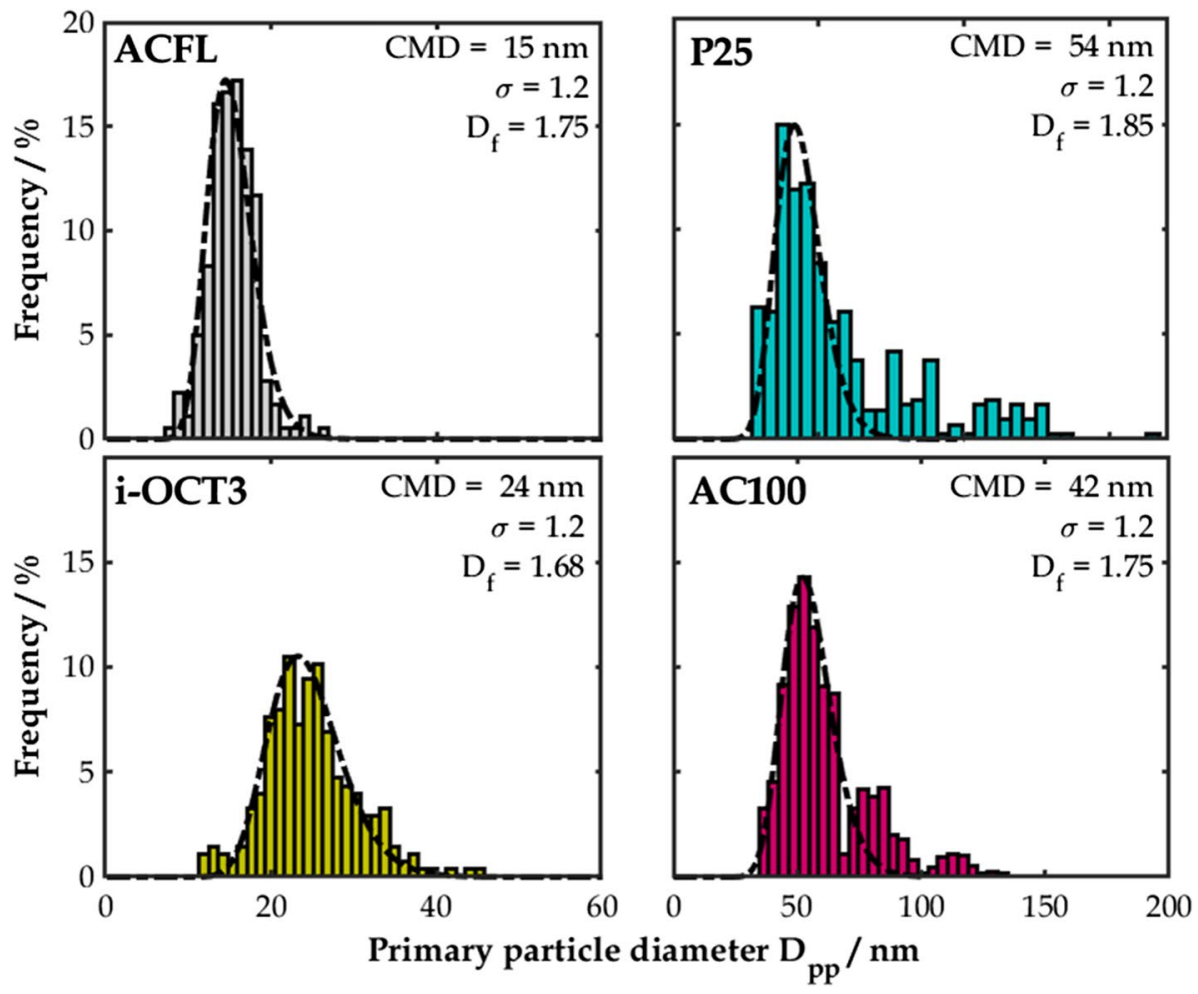

Fig. 7 Primary particle size distributions and morphological properties of soot samples from Table 1 calculated with the procedure outlined in Sect. 2.2.3; dashed curves correspond to fitted log-normal distributions

could be the manual selection of regions of interest (ROI) favoring images with high contrast (Yehliu et al. 2011a, b; Palotas et al. 1996; Wan et al. 2018). The image processing algorithm used here analyzes full frame HRTEM images $(120 \mathrm{~nm} \times 120 \mathrm{~nm})$ including also short structures with comparably less contrast.

The slope of the fringe length distribution with a logarithmic scale on the frequency axis is larger for the highly reactive sample (AGFG) than that of the less reactive sample (ACFL). This indicates a broader distribution for ACFL, though in the evaluated image fringes with large lengths have not been detected. Missing of large fringe lengths could be by chance due to the selection of the region of interest in the image. A broader distribution of the fringe length corresponds to a narrower distribution of the separation distances, which has been measured for this image.

The resulting structure-reactivity correlation is depicted in Fig. 10, where the mean fringe length of the primary particles is plotted versus $T_{\max }$. The error bars in the plot are due to the evaluation of up to 5000 structures from primary particles in different HRTEM images and represent the variation of the evaluated mean lengths from different primary particles. The correlation is approximated by a linear fit in Fig. 10. The correlation depicted in Fig. 10 holds for the different types of soot obtained from different sources, e.g. flame soot, carbon blacks, engine soot and spark discharge generated soot.

UV-visible absorption spectra affirm qualitatively the structure-reactivity correlation, see Fig. 11. The shape of the spectra is similar to that resulting from soot analyzed 

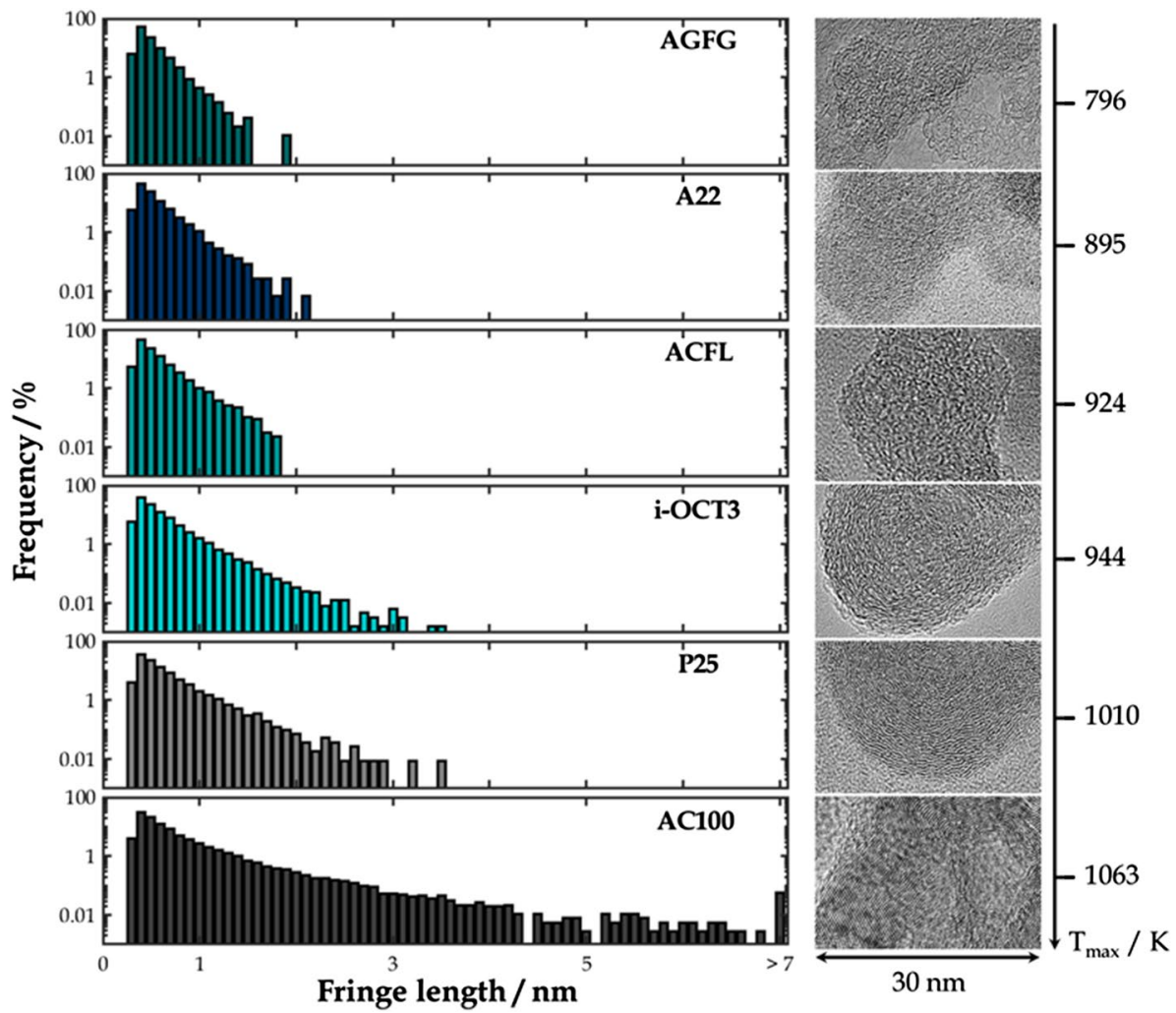

Fig. 8 Fringe length distributions of primary particles from soot samples from Table 1 evaluated with the procedure outlined in Sect. 2.2.3

in Apicella et al. (2004). All soot samples exhibit highest absorption at $290 \mathrm{~nm}$, which decreases towards larger wavelengths. The decay is lowest for the soot sample with lowest reactivity $\left(\mathrm{AC} 100, \mathrm{~T}_{\max }=1063 \mathrm{~K}\right)$. For P25 $\left(\mathrm{T}_{\max }=1010 \mathrm{~K}\right)$ after an initially steep decrease of the normalized absorption, a slightly steeper decrease compared with AC100 at larger wavelengths is observed. For the highly reactive soot samples AGFG, ACFL and i-OCT3 with $\mathrm{T}_{\max }$ around $911 \mathrm{~K}$ to $944 \mathrm{~K}$ after an initially steep decrease, the normalized absorbance decays similarly at larger wavelengths, however, somehow steeper than for the low reactive soot samples. For the latter samples different absorbance of molecular feature at 450-500 nm, least pronounced for ACFL, and slight shift of contained bands occurs.

The fringe length $\mathrm{L}$ is a measure for the spatial extension of graphene-like layers in the primary particles. Along with an increase of the extension of a graphene-like layer, the contribution of planar $\mathrm{sp}^{2}$-bonded carbon atoms and thereby $\pi$-electrons rises. Large contributions of $\pi$-electrons corresponding to large extension of graphene-like layers cause a redshift of absorption and only a smooth decline of the absorption functions with increasing wavelength (Apicella et al. 2004). Small contributions of $\pi$-electrons cause a steep decrease. Relative to the total number of electrons, large mean fringe lengths (AC100) provide the largest number density of $\pi$-electrons and only smooth decline of the absorption function whereas small mean fringe lengths (AGFG) provide the smallest number density of $\pi$-electrons and a steep decrease of the absorption function. This is reflected plotting the 


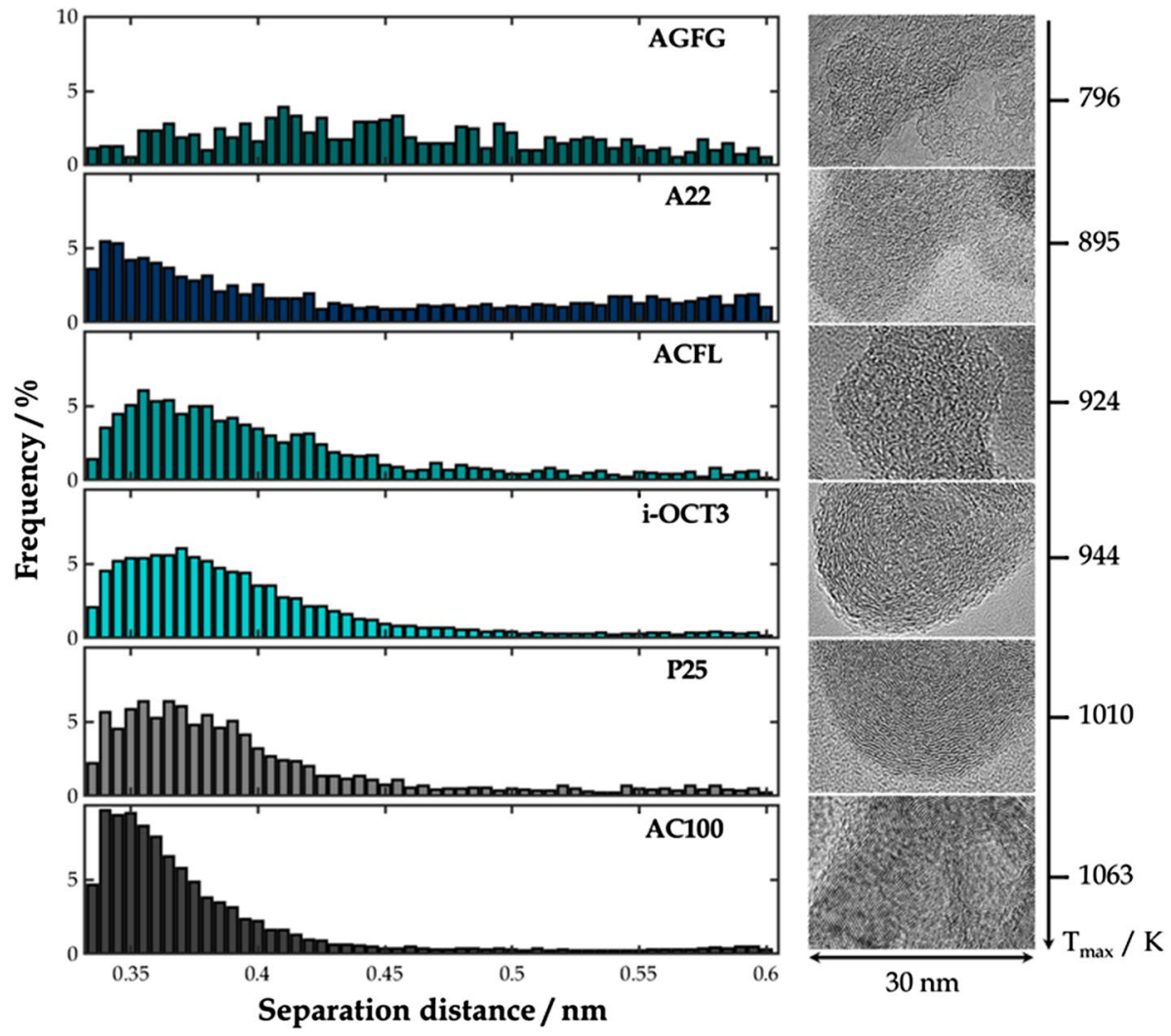

Fig. 9 Fringe separation distances distributions of primary particles from soot samples from Table 1 evaluated with the procedure outlined in Sect. 2.2.3

Fig. 10 Correlation of mean fringe length $\mathrm{L}_{\mathrm{f}}$ of the soot primary particles versus $\mathrm{T}_{\max }$ for the soot samples from Table 1

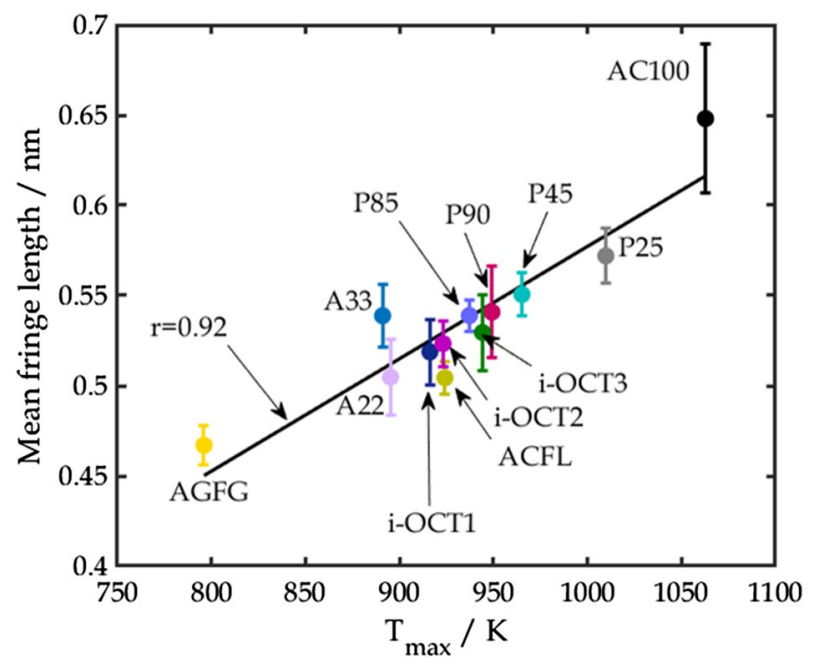


Fig. 11 Normalized UV-vis spectra of soot samples from Table 1
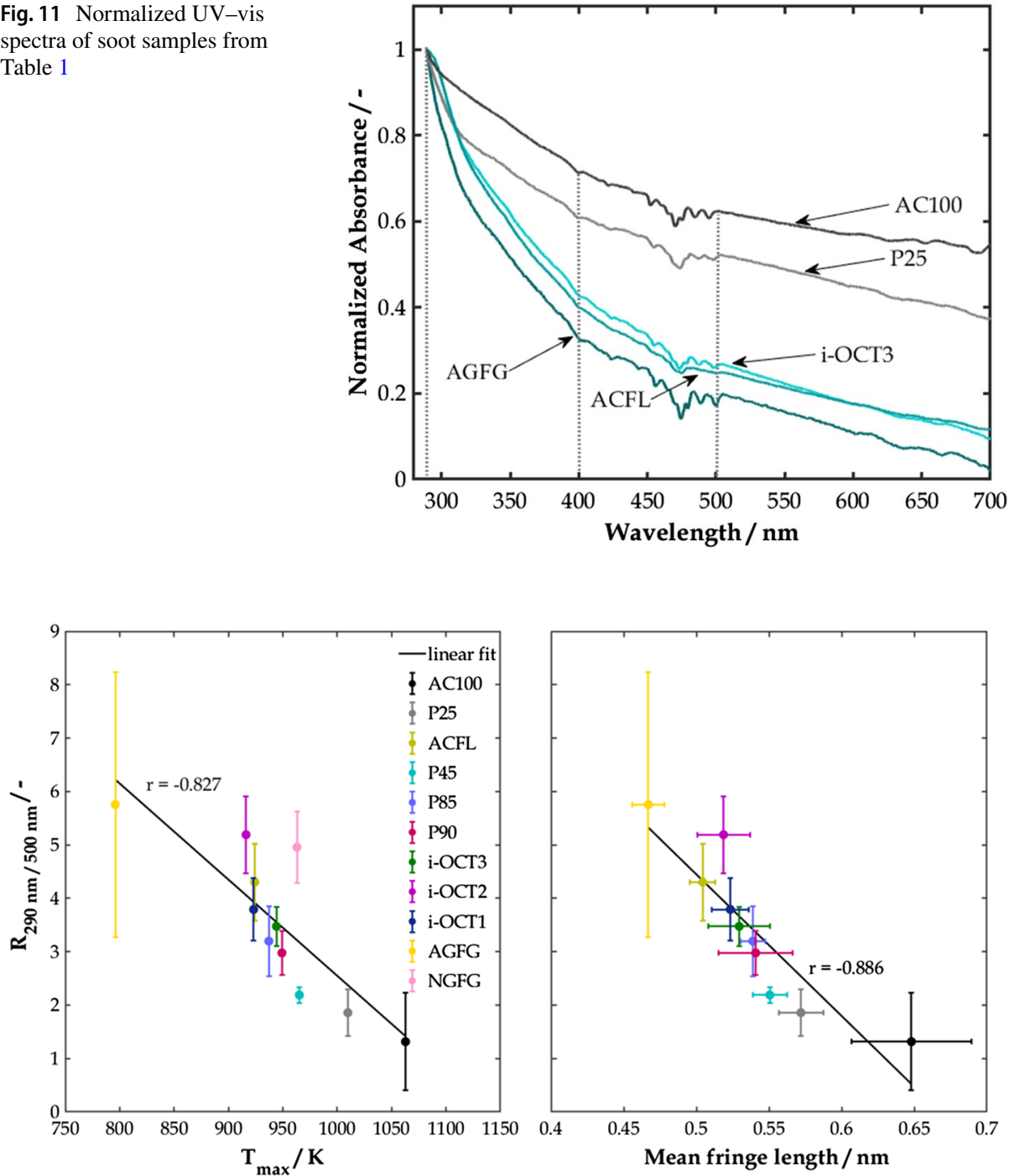

Fig. 12 Ratio $\mathrm{R}$ of the absorption function at $290 \mathrm{~nm}$ to that at $500 \mathrm{~nm}$ versus $\mathrm{T}_{\max }$ and mean fringe length, resp., of soot samples from Table 1

ratio of the absorption function at different wavelengths versus $\mathrm{T}_{\max }$, the temperature of maximum oxidation rate during TPO, or the fringe lengths, see Fig. 12. Again the resulting correlations are approximately linear. The error bars in the plot are due to the evaluation of up to four spectra from different portions of the same soot sample.

As exemplified by Fig. 6 the oxidation rates of soot samples with multiple $\mathrm{T}_{\max }$ are reproduced by a linear combination of the oxidation rates of different soot types with the respective $\mathrm{T}_{\max }$ (or $\mathrm{T}_{\max }$ in the respective range). The interpretation of this behavior is that the single soot types are oxidized independently. If the extension of the fringe layers is the essential parameter describing the reactivity, the linear combination should also apply to 

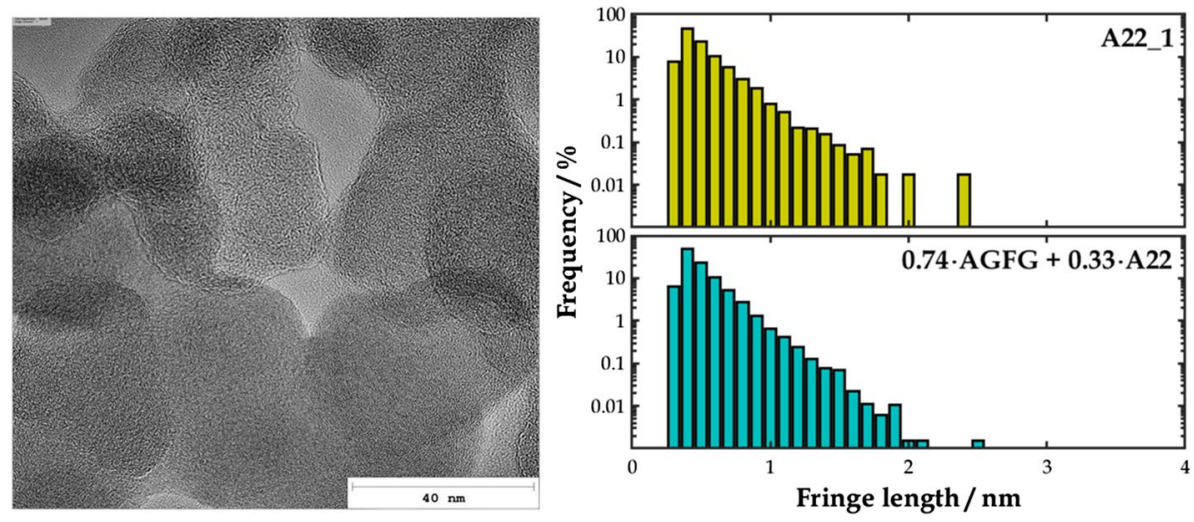

Fig. 13 HRTEM image of primary particles of the sample A22_1 (left), distribution of the fringe length of that sample (upper right) and that calculated from the linear combination of the distributions of AGFG and A22 (lower right)

the distributions of the fringe length. This is demonstrated in Fig. 13 for the soot sample A22_1, the TPO profile of which is given in Fig. 6. The figure contains a HRTEM image including some primary particles of that sample (left) and the distribution of the fringe length evaluated from that image (upper right). The fringe length distribution of an artificial mixture with $0.74 * \mathrm{AGFG}+0.33 * \mathrm{~A} 22$ composed by a linear combination of the distributions of AGFG and A22 is given in the lower right part of Fig. 13. The two distributions show a reasonable correspondence. Due to the shape of the fringe length distributions no polydisperse distribution as in the TPO profiles for the linear combination is expected.

This behavior can be verified also for other mixtures as given in Fig.14. The figure contains the experimental TPO profile (red symbols) of a prepared 1:1 mixture of the P25 and i-OCT3 samples and a TPO profile composed from the TPO profiles of these soot samples (red solid line). The upper right part of the figure displays an exemplary HRTEM image including some primary particles of that mixture. Finally, the fringe length distribution evaluated from up to 5000 fringes from mixed primary particles in different HRTEM images of that mixture (lower right) and that calculated from the linear combination of the distributions of P25 and i-OCT3 (lower left) is displayed. In difference to Fig. 13 the figure contains the HRTEM and the fringe length distributions of the prepared mixture from the respective experiments. Again a good agreement between the two distributions is observed.

An intermediate conclusion - as argued by e.g. Bhardwaj et al. (2014), Lapuerta et al. (2012), Vander Wal and Tomasek (2003) — is that the nanostructure of the soot primary particles essentially determines their reactivity against oxidation. A simple reactivity-nanostructure relation approximately linearly correlates the mean length of the fringes in the primary particles with $\mathrm{T}_{\max }$. Furthermore, oxidation rates of soot samples with differently reactive components can be linearly combined to the apparent oxidation rate.

\subsection{Stepwise Oxidation of Soot}

If the extension of the fringe layers is the essential property that determines reactivity, the reactivity of soot should increase with deceasing length of the fringes. Decreasing length of the fringes is expected during oxidation of soot particles and, therefore, the reactivity should increase during oxidation. 

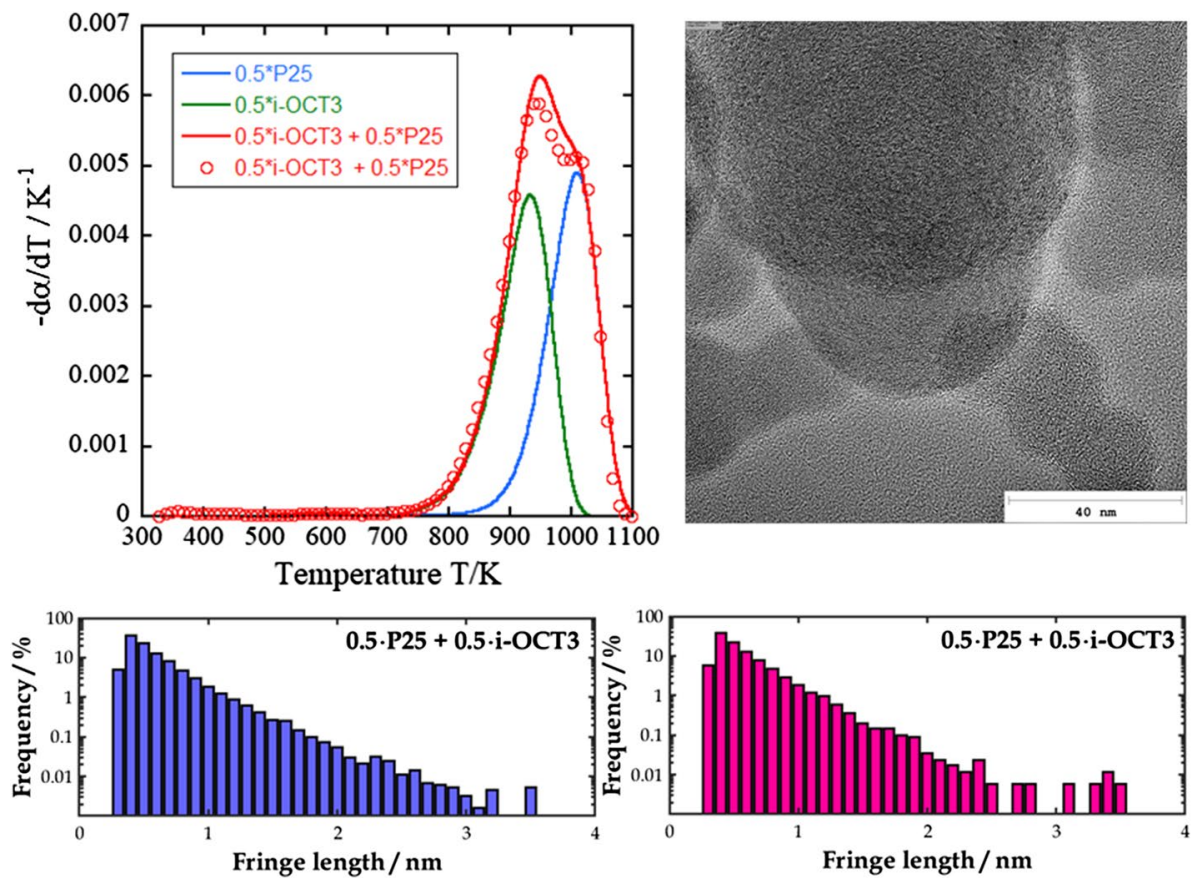

Fig. 14 TPO profile of a prepared mixture with $0.5 * \mathrm{P} 25+0.5 * \mathrm{i}$-OCT3 (upper left), HRTEM image of primary particles of that mixture (upper right), distribution of the fringe length from the HRTEM image of that mixture (lower right) and that calculated from the linear combination of the distributions of P25 and i-OCT3 (lower left)

To test this hypothesis, different soot samples were oxidized as described in Sect. 2.2.1 repeatedly with oxygen under isothermal conditions at $1073 \mathrm{~K}$. After each oxidation stage with mass decreases of $20 \%, 60 \%, 80 \%$ and $90 \%$ soot primary particles were examined with regard to their reactivity by TPO and HRTEM analysis.

Figure 15 shows the TPO profiles of two soot samples from these test series (i-OCT3 and $\mathrm{P} 25$ ). The figure demonstrates the decrease in $\mathrm{T}_{\max }$, i.e. increase in reactivity, with increasing mass loss due to oxidation, which is more pronounced for the more reactive carbon blacks (i-OCT3: $944 \mathrm{~K}$ to $860 \mathrm{~K}, \mathrm{P} 25$ : $1010 \mathrm{~K}$ to $964 \mathrm{~K}, \mathrm{AC} 100$ : $1063 \mathrm{~K}$ to 1052 $\mathrm{K}$ ) than for the less reactive ones. The temperature at maximum oxidation rate, $\mathrm{T}_{\max }$, is dependent on the kinetics of oxidation and connected to the apparent activation energy of the oxidation, compare Sect. 2.2.1. A change of $\mathrm{T}_{\max }$ by $10 \mathrm{~K}$ results in a change of the activation energy of about $1.5 \mathrm{~kJ} \mathrm{~mol}^{-1}$. The decrease of $\mathrm{T}_{\max }$ with proceeding burn-out is steeper at burn-out ratios larger than $60 \%$ compared with lower burn-out ratios. The analysis of the nanostructure of the primary particles from these two soot samples confirms this development, as given in Figs. 16 and 17. The decrease in $\mathrm{T}_{\max }$ from $944 \mathrm{~K}$ of the untreated sample i-OCT3 to approx. $860 \mathrm{~K}$ during oxidation up to a mass decrease of $90 \%$ is associated with a significant decrease in the expansion of the graphene-like layers in the primary particles (Fig. 16, left part). It is interesting that the size distribution of the primary particles hardly changes during the stepwise oxidation (Fig. 16, right part), suggesting an internal burning mode rather than a shrinking core mode. The same trend can be seen for the sample P25 in Fig. 17 and ACFL and AC100 

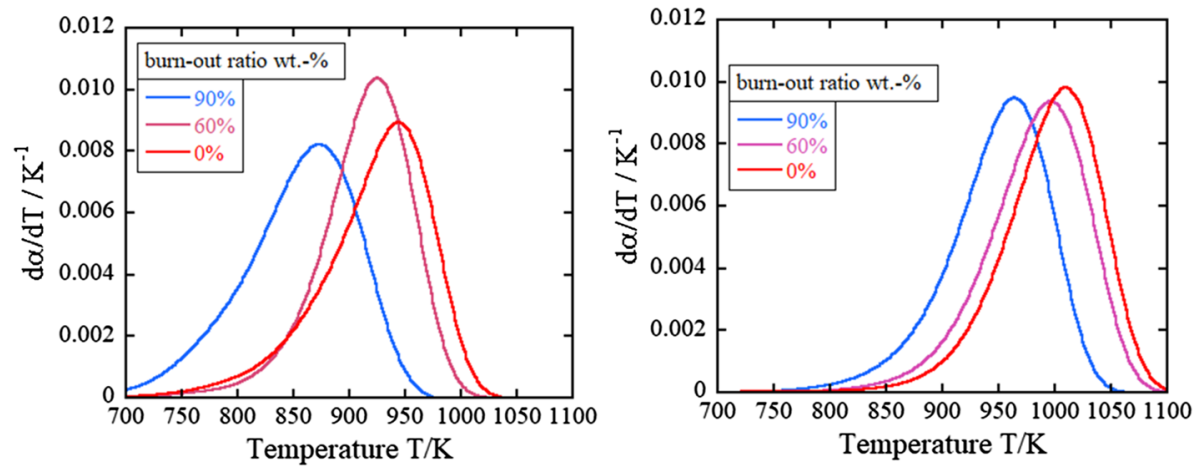

Fig. 15 TPO profiles of i-OCT3 (left) and P25 (right) at stepwise oxidation
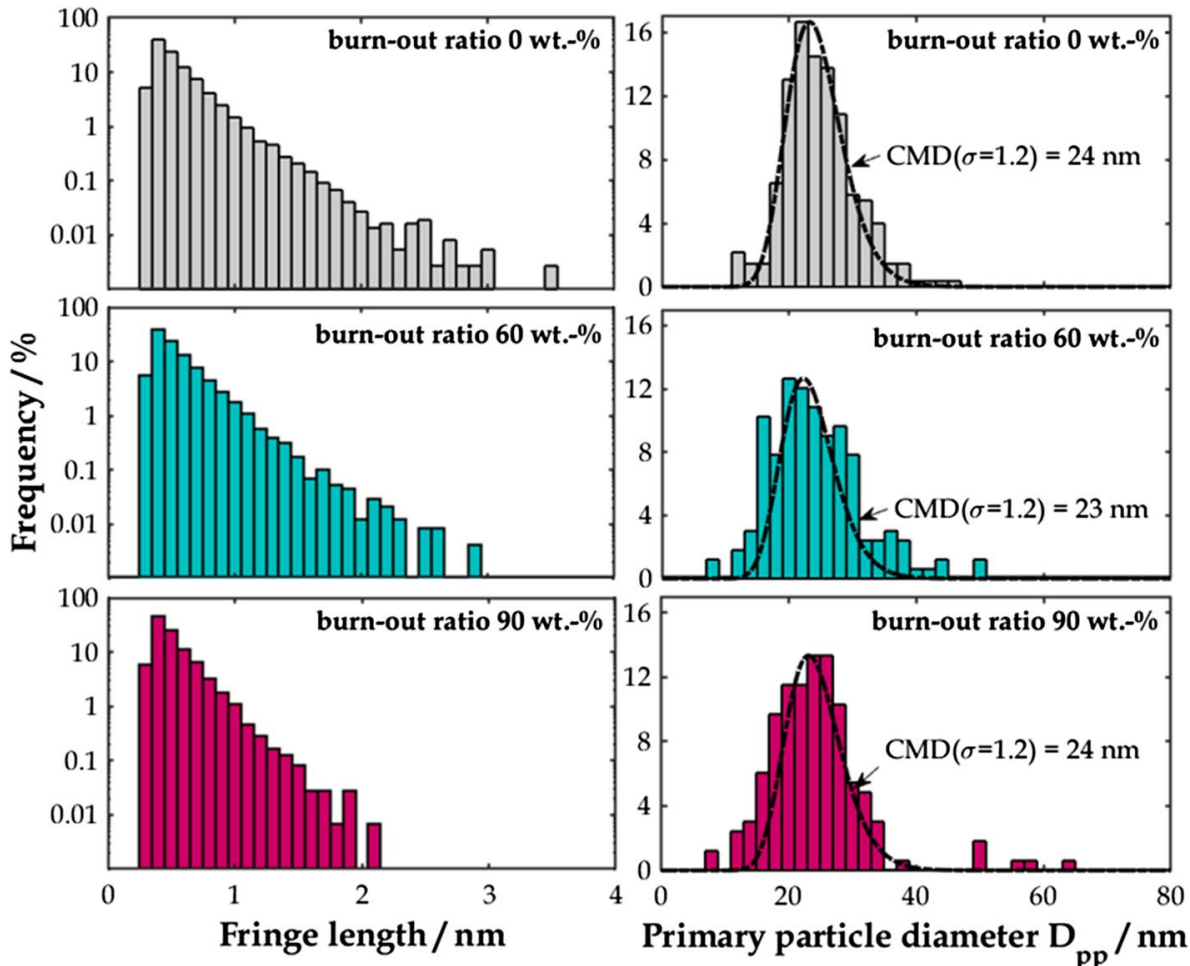

Primary particle diameter $\mathrm{D}_{\mathrm{pp}} / \mathrm{nm}$

Fig. 16 Fringe length distribution of primary particles from i-OCT3 and primary particle size distribution at stepwise oxidation

(not depicted here). At the prevailing large time scales for the oxidation of soot diffusion rates of oxygen into the structures of the primary particles well competes with chemical reaction rates. Similar behavior has also been observed in the oxidation of soot catalyzed with $\mathrm{Fe}_{2} \mathrm{O}_{3}$ under similar conditions (Reichert et al. 2010) and in flames (Schäfer et al. 1995). 


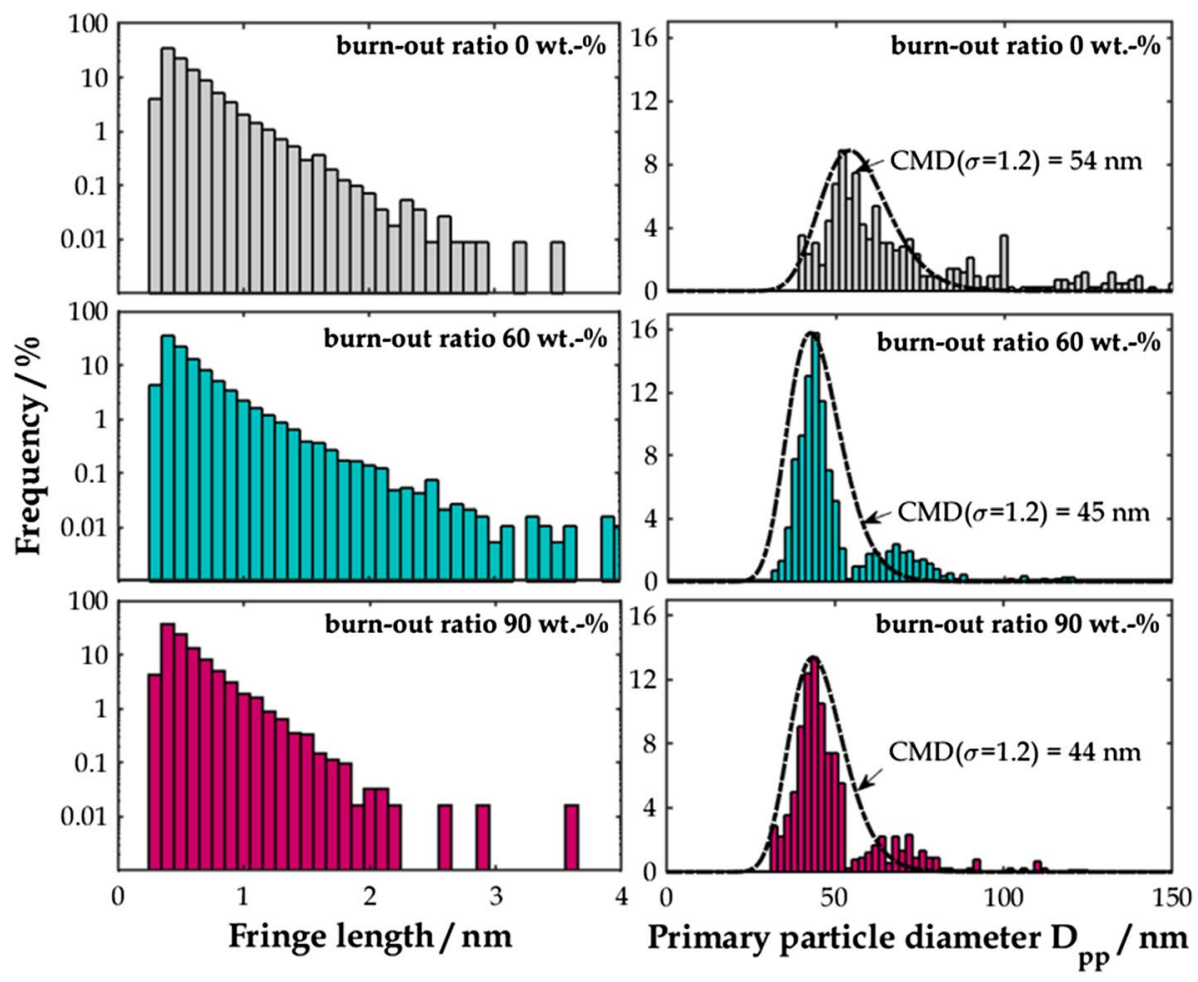

Fig. 17 Fringe length distribution of primary particles from P25 and primary particle size distribution at stepwise oxidation

Similar interesting features can be extracted from Raman scattering results given in Fig. 18. The figure displays stacked Raman spectra of primary particles from i-OCT3 at stepwise oxidation (left) and the evaluation of $\mathrm{I}_{\mathrm{D} 1} / \mathrm{I}_{\mathrm{G}}$ according to the procedure described in Sect. 2.2.2 (right). ${ }^{1}$ The graphite band (G band) at about $1580 \mathrm{~cm}^{-1}$ is attributed to an ideal graphitic lattice and indicates highly ordered structures. The D1-peak at about $1355 \mathrm{~cm}^{-1}$ becomes active only in presence of disordered graphene-like structures. The estimation of the relative intensities of D1- and G-bands using the 5 band fitting procedure, therefore, provides qualitative information about the abundance of graphitic ordered structures and disordered regions in the primary particles. High values of $\mathrm{I}^{\mathrm{D} 1} / \mathrm{I}_{\mathrm{G}}$ indicate predominance of low ordered graphene-like structures with small extension whereas low values suggest well ordered, graphitic graphene-like structures of large extension.

The spectra of i-OCT3 at different burn-out ratios in Fig. 18 give a qualitative picture of the evolution of the intensity ratio, and the quantitative evaluation is displayed in the right part of Fig. 18. The intensity ratio $\mathrm{I}_{\mathrm{D} 1} / \mathrm{I}_{\mathrm{G}}$ is initially high for virgin soot i-OCT3 and decreases to about less than half and decreases further slightly with progressing oxidation until a burn-out ratio of $80 \%$. At higher burn-out ratio it increases again, indicating that the

\footnotetext{
1 The 5 band fitting procedure for i-OCT3 at a burn-out ratio of $0 \%$ indicating the D1- and G-peaks is demonstrated in Fig. 2, to keep the figure clear, the fitting procedure is not indicated in Fig. 18.
} 

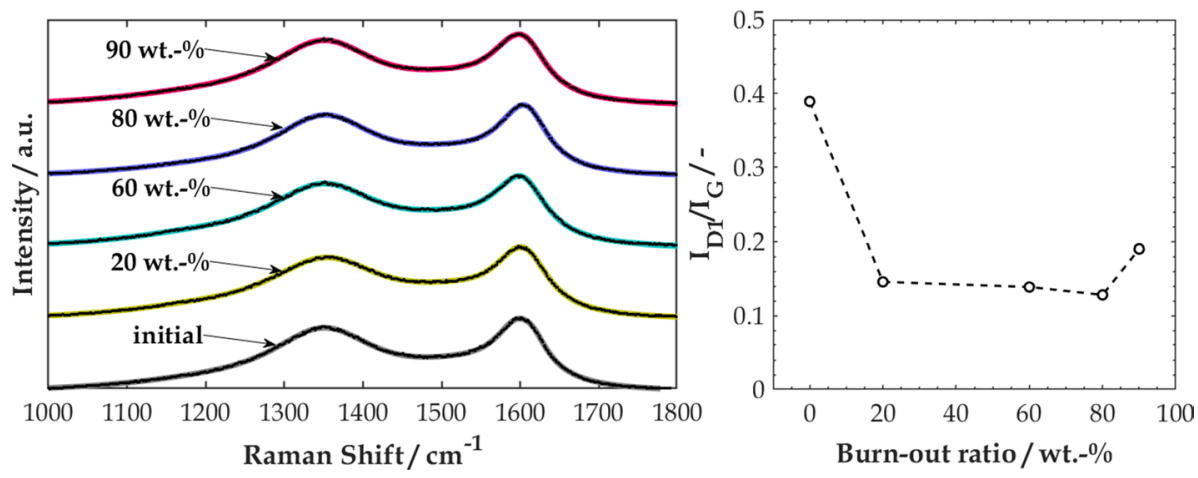

Fig. 18 Raman spectra of primary particles from i-OCT3 (left) at stepwise oxidation and evaluation of $\mathrm{I}_{\mathrm{D} 1} / \mathrm{I}_{\mathrm{G}}$ according to the procedure described in Sect. 2.2.2 (right)

relative abundance of ordered regions within the primary particles increases on account of the disordered amorphous regions. At high burn-out ratios also the highly ordered structures decompose. This behavior suggests that the very reactive, disordered structures are first oxidized, while the less reactive structures, whose reactivity nevertheless increases during the oxidation, see Fig. 15, are later oxidized and degraded finally to smaller structures. Similar trends can be found for e.g. AGFG and NGFG, where the different reactivity against oxidation can be traced back to the relative abundance of ordered and disordered graphene layer structures and is reflected by the Raman spectra of these soot types (Hagen et al. 2020).

\subsection{Mechanistic Interpretation}

As discussed in Sect. 2.2.4, in this work as well as in similar work from literature, see e.g. Sendt and Haynes (2011), Edwards et al. (2013, (2014), Frenklach and Mebel (2020), the mechanistic interpretation of the oxidation of soot is based on model molecules. These are supposed to depict the graphene-like structures in the primary soot particles omitting interactions between the single layers. The employed model molecules-in this work pyrene-are approximations with regard to the energy levels of the individual carbon atoms in the graphene-like structures. However, they facilitate the identification of essential reaction pathways for reactions of the graphene-like layers with $\mathrm{O}_{2}$ and for estimating and comparing reaction rate coefficients. These limitations restrict the focus of the following discussion to clearly identifiable trends.

The experimental results discussed in the previous sections reveal that the property determining reactivity is predominantly the fringe length of graphene layers. The larger the fringe length the lower the reactivity. Soot types with different reactivity are characterized by different fringe sizes. Different soot types combined in a soot primary particle contain regions of different fringe length which are oxidized independently leading to multiple peaks in the TPO traces with different $\mathrm{T}_{\max }$, see Sect. 3.2. The independent oxidation of graphene layers of different reactivity suggests, that after primary activation of a graphene-like structure the further degradation proceeds at higher reaction rate than the activation of additional layers. Another experimental result is the increasing reactivity of 


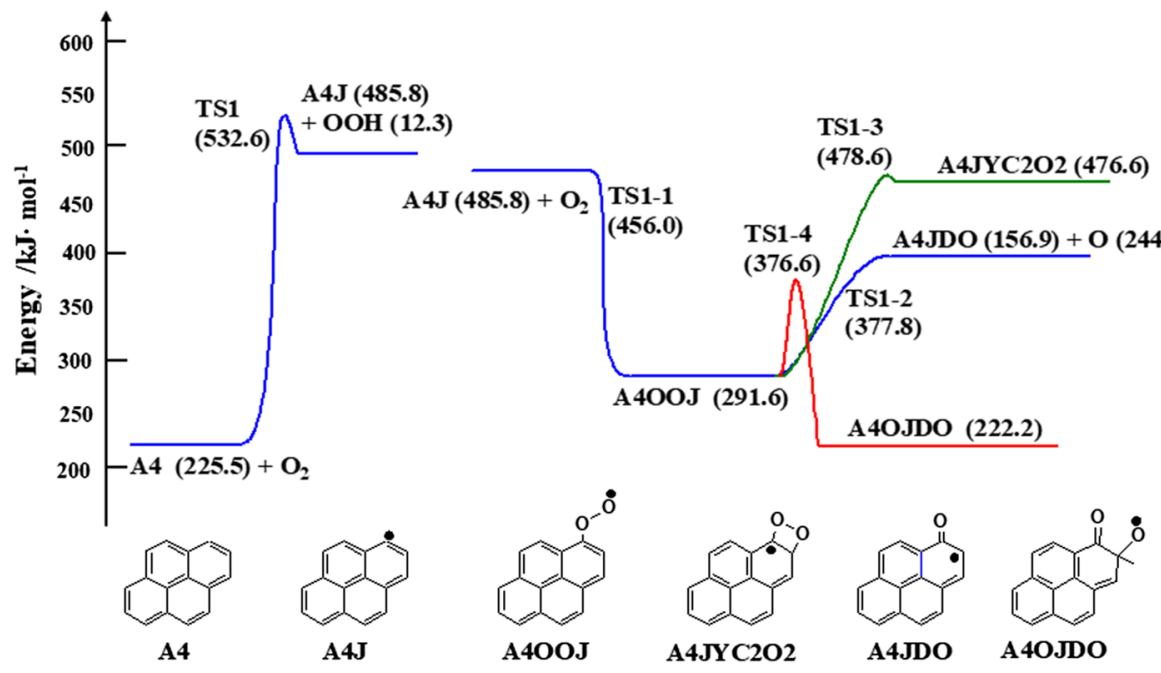

Fig. 19 Energy diagram for the primary attack of $\mathrm{O}_{2}$ at pyrene and follow-up reactions with $\mathrm{O}_{2}$ via reaction path a (blue), reaction path $\mathrm{b}$ (green) and reaction path $\mathrm{c}$ (red); structures of the involved species are also indicated in the diagram

the graphene layers with proceeding oxidation, see Sect. 3.3. The mechanistic interpretation of the experiments given in the following is intended to reflect these results.

The primary attack of $\mathrm{O}_{2}$ on the graphene-like layers - represented by the pyrene model molecule-can take place on edge $\mathrm{C}-\mathrm{H}$ sites in a sequence of three edge $\mathrm{C}$-H-sites as depicted in the energy diagram Fig. 19. ${ }^{2}$ The attack of $\mathrm{O}_{2}$ at internal carbon atoms or at edge carbon atoms or at $\mathrm{C}-\mathrm{H}$-sites in sequences with only two edge $\mathrm{C}-\mathrm{H}$-sites, which may result in different energy barriers, is not detailed here, because it is followed by a complex reaction system contributing little to the degradation of the polycyclic structure. The energy diagram illustrates the attack of $\mathrm{O}_{2}$ on pyrene A4 via abstraction of a hydrogen from a $\mathrm{C}-\mathrm{H}$-site forming a pyrenyl radical, $\mathrm{A} 4 \mathrm{~J}+\mathrm{OOH}$. The $\mathrm{H}$-abstraction occurs via transition state TS1 representing an energy barrier of $307.1 \mathrm{~kJ} \mathrm{~mol}^{-1}$ relative to pyrene and $\mathrm{O}_{2}$. The respective rate coefficient fitted to the format $k_{0} \cdot \exp \left[-\frac{E_{a}}{R \cdot T}\right]$ is given in Table 3 .

The experimental reaction rate coefficients according to Eq. 4 are in the order of magnitude of $k_{o x}^{(4)} \approx 5 \cdot 10^{6} \cdot \exp \left[-\frac{150}{R \cdot T}\right] \mathrm{K}^{-1}$, see Table 2 , with $\mathrm{E}_{\mathrm{a}}$ in $\mathrm{kJ} \mathrm{mol}^{-1}$. Considering the heating rate of $5 \mathrm{~K} \mathrm{~min}^{-1}$, this results in rate coefficients at $900 \mathrm{~K}$ (which is the temperature range for maximum conversion rates) of $k_{o x(900 K)}^{(3)} \approx 8 \cdot 10^{-4} \mathrm{~s}^{-1}$. The corresponding time scale then amounts to about $20 \mathrm{~min}$. The reaction rate coefficient of the $\mathrm{H}$-abstraction, reaction (1), amounts to $1.1 \cdot 10^{12} \cdot \exp \left[-\frac{325.3}{R \cdot T}\right] \mathrm{cm}^{3} \mathrm{~mol}^{-1} \mathrm{~s}^{-1}$. Assuming constant $\mathrm{O}_{2}$ concentration of $5 \% \mathrm{vol}$ this results in $k_{(900 K)}^{(1)} \approx 1 \cdot 10^{-13} \mathrm{~s}^{-1}$. Compared with the measured rate coefficients for the oxidation of soot the rate coefficient for the activation of the graphene

\footnotetext{
2 To facilitate reading of the energy diagrams, all structures of the molecules involved in the oxidation reactions are also displayed. For simplicity abbreviations are used for the structures. Here Ax means x sixmembered rings, $\mathrm{Ax}^{\cdot}$ or $\mathrm{AxJ}$ describes the corresponding radical, $\cdot$ or $\mathrm{J}$ is a radical site, $\mathrm{D}$ stands for a double-bond and Y means a cyclic structure. TS is a transition state structure.
} 
Table 3 Reaction rate parameters for the reactions given in Figs. 19, 20, 21, 22, 23

\begin{tabular}{lllll}
\hline Reaction & No. & $k_{0}\left(\right.$ in $\left.\mathrm{cm}^{3}, \mathrm{~mol}, \mathrm{~s}\right)$ & $\mathrm{E}_{\mathrm{a}}\left[\mathrm{kJ} \mathrm{mol}^{-1}\right]$ & $\begin{array}{l}\mathrm{k}^{(900 \mathrm{~K})}(\mathrm{in} \\
\mathrm{cm}^{3}, \mathrm{~mol}, \\
\mathrm{~m})\end{array}$
\end{tabular}

Activation by $\mathrm{O}_{2}$

$$
\mathrm{A} 4+\mathrm{O}_{2} \rightarrow \mathrm{A} 4 \mathrm{~J}+\mathrm{OOH}
$$

$1.1 \cdot 10^{12}$

325.3

$1.5 \cdot 10^{-7}$

Activation by radicals

$$
\begin{aligned}
& \mathrm{A} 4+\mathrm{OOH} \rightarrow \mathrm{A} 4 \mathrm{~J}+\mathrm{H}_{2} \mathrm{O}_{2} \\
& \mathrm{~A} 4+\mathrm{OH} \rightarrow \mathrm{A} 4 \mathrm{~J}+\mathrm{H}_{2} \mathrm{O} \\
& \mathrm{A} 4+\mathrm{O} \rightarrow \mathrm{A} 4 \mathrm{~J}+\mathrm{OH}
\end{aligned}
$$$$
\text { (2) } 1.1 \cdot 10^{9}
$$

$$
1.9 \cdot 10^{12}
$$

65.0

$1.9 \cdot 10^{5}$

Follow-up reactions (path $\mathrm{a}, \mathrm{b}, \mathrm{c}$ )

$$
\begin{aligned}
& \mathrm{A} 4 \mathrm{~J}+\mathrm{O}_{2} \rightarrow \mathrm{A} 4 \mathrm{OOJ} \\
& \mathrm{A} 4 \mathrm{OOJ} \rightarrow \mathrm{A} 4 \mathrm{JDO}+\mathrm{O} \\
& \mathrm{A} 4 \mathrm{OOJ} \rightarrow \mathrm{A} 4 \mathrm{OJDO} \\
& \mathrm{A} 4 \mathrm{OOJ} \rightarrow \mathrm{A} 4 \mathrm{JYC} 2 \mathrm{O} 2
\end{aligned}
$$

$8.4 \cdot 10^{9}$

$6.4 \cdot 10^{13}$

$6.4 \cdot 10^{13}$

$6.9 \cdot 10^{12}$

$-4.96$

$3.7 \cdot 10^{12}$

49.8

$4.1 \cdot 10^{8}$

Follow-up reactions (path a1)

$$
\begin{aligned}
& \mathrm{A} 4 \mathrm{JDO}+\mathrm{O}_{2} \rightarrow \mathrm{A} 4 \mathrm{DOO} 2 \mathrm{~J} \\
& \mathrm{~A} 4 \mathrm{DOO} 2 \mathrm{~J} \rightarrow \mathrm{A} 4 \mathrm{JDOYC} 2 \mathrm{O} 2 \\
& \mathrm{~A} 4 \mathrm{JDOYC} 2 \mathrm{O} 2 \rightarrow \mathrm{A} 3 \mathrm{JDODODO} \\
& \mathrm{A} 3 \mathrm{JDODODO} \rightarrow \mathrm{A} 3 \mathrm{JDODO}+\mathrm{CO} \\
& \mathrm{A} 3 \mathrm{JDODO} \rightarrow \mathrm{A} 3 \mathrm{~J}+2 \mathrm{CO}
\end{aligned}
$$

$\begin{array}{ll}\text { (9) } & 2.2 \cdot 10^{5} \\ \text { (10) } & 1.3 \cdot 10^{12} \\ \text { (11) } & 1.5 \cdot 10^{13} \\ \text { (12) } & 1.9 \cdot 10^{13} \\ \text { (13) } & 3.6 \cdot 10^{14}\end{array}$

138.8

$7.3 \cdot 10^{1}$

91.2

$3.2 \cdot 10^{8}$

89.9

$3.8 \cdot 10^{8}$

206.2

$7.4 \cdot 10^{0}$

Follow-up reactions (path a2)

$$
\begin{aligned}
& \text { A4JDO }+\mathrm{O} \rightarrow \mathrm{A} 4 \mathrm{OJDO} \\
& \text { A4OJDO } \rightarrow \text { A4JDOYC2O } \\
& \text { A4JDOYC2O } \rightarrow \text { A3YC5OCJDO } \\
& \text { A3YC5OCJDO } \rightarrow \text { A3C2JCOCO } \\
& \text { A3C2JCOCO } \rightarrow \text { A3C2JCO + CO } \\
& \text { A3C2JCO } \rightarrow \text { A3JYC5DO } 1 \\
& \text { A3JYC5DO1 } \rightarrow \text { A3JYC5DO3 } \\
& \text { A3JYC5DO3 } \rightarrow \text { A3CJ + CO }
\end{aligned}
$$

$2.0 \cdot 10^{11}$

$7.5 \cdot 10^{11}$

(16) $2.9 \cdot 10^{13}$

(17) $5.2 \cdot 10^{13}$

(18) $9.4 \cdot 10^{14}$

(19) $4.0 \cdot 10^{13}$

(20) $2.1 \cdot 10^{13}$

(21) $2.4 \cdot 10^{14}$

70.6

$1.75 \cdot 10^{1}$

72.5

$8.1 \cdot 10^{7}$

$-3.58$

$2.4 \cdot 10^{13}$

237.6

$3.2 \cdot 10^{-1}$

221.1

$5.3 \cdot 10^{1}$

Follow-up reactions (path bc1)

$$
\begin{aligned}
& \text { A4OJDO } \rightarrow \text { A3YC6JODO } \\
& \text { A3YC6JODO } \rightarrow \text { A3CCDOCJDO } \\
& \text { A4JYC2O2 } \rightarrow \text { A3CCDOCJDO } \\
& \text { A3CCDOCJDO } \rightarrow \text { A3JCCDO }+ \text { CO } \\
& \text { A3JCCDO } \rightarrow \text { A3CCJDO } \\
& \text { A3CCJDO } \rightarrow \text { A3CJ }+ \text { CO }
\end{aligned}
$$

$$
5.9 \cdot 10^{12}
$$$$
\text { (23) } 1.1 \cdot 10^{13}
$$$$
\text { (24) } 6.9 \cdot 10^{13}
$$

(25) $1.9 \cdot 10^{16}$

$-11.9$

$1.0 \cdot 10^{12}$

$-12.8$

$4.2 \cdot 10^{12}$

113.5

$7.7 \cdot 10^{6}$

175.4

$3.4 \cdot 10^{3}$

306.3

$1.5 \cdot 10^{-3}$

23.3

$1.8 \cdot 10^{12}$

257.0

$2.5 \cdot 10^{-2}$

212.6

$1.0 \cdot 10^{2}$

(26) $4.3 \cdot 10^{12}$

$2.0 \cdot 10^{12}$

29.4

$1.1 \cdot 10^{11}$

143.9

$4.9 \cdot 10^{4}$

$-251.8$

$2.8 \cdot 10^{28}$

83.7

$2.6 \cdot 10^{11}$

$-11.5$

$2.0 \cdot 10^{13}$

215.9

$6.0 \cdot 10^{-1}$

Follow-up reactions (path bc11, bc12)

$$
\begin{aligned}
& \mathrm{A} 3 \mathrm{CJ}+\mathrm{O} \rightarrow \mathrm{A} 3 \mathrm{JCDO} \\
& \mathrm{A} 3 \mathrm{JCDO} \rightarrow \mathrm{A} 3 \mathrm{CJDO} \\
& \mathrm{A} 3 \mathrm{CJDO} \rightarrow \mathrm{A} 3 \mathrm{~J}+\mathrm{CO} \\
& \mathrm{A} 3 \mathrm{CJ}+\mathrm{O}_{2} \rightarrow \mathrm{A} 3 \mathrm{COOJ} \\
& \mathrm{A} 3 \mathrm{COOJ} \rightarrow \mathrm{A} 3 \mathrm{JYCO} 2 \\
& \mathrm{~A} 3 \mathrm{JYCO} 2 \rightarrow \mathrm{A} 3 \mathrm{YCJO} 2
\end{aligned}
$$

$1.5 \cdot 10^{11}$

$4.1 \cdot 10^{13}$

$$
2.3 \cdot 10^{12}
$$

$4.6 \cdot 10^{4}$

$2.7 \cdot 10^{13}$

$6.4 \cdot 10^{12}$

$-117.9$

$1.0 \cdot 10^{18}$

266.2

$1.4 \cdot 10^{-2}$

9.3

$6.6 \cdot 10^{11}$

(34) $1.8 \cdot 10^{12}$

$-26.8$

$1.7 \cdot 10^{6}$

72.9

$1.5 \cdot 10^{9}$

310.6

$6.0 \cdot 10^{-6}$

$-147.4$

$6.6 \cdot 10^{20}$ 
Table 3 (continued)

\begin{tabular}{lcccc}
\hline Reaction & No. & $k_{0}\left(\mathrm{in} \mathrm{cm}^{3}, \mathrm{~mol}, \mathrm{~s}\right)$ & $\mathrm{E}_{\mathrm{a}}\left[\mathrm{kJ} \mathrm{mol}^{-1}\right]$ & $\begin{array}{l}\mathrm{k}^{(900 \mathrm{~K})} \text { (in } \\
\mathrm{cm}^{3}, \mathrm{~mol}, \\
\mathrm{~s})\end{array}$ \\
\hline $\mathrm{A} 3 \mathrm{JYCO} 2 \rightarrow \mathrm{A} 3 \mathrm{JDCO} 2$ & $(35)$ & $2.3 \cdot 10^{12}$ & 240.9 & $2.3 \cdot 10^{-2}$ \\
$\mathrm{~A} 3 \mathrm{JDCO} 2 \rightarrow \mathrm{A} 3 \mathrm{~J}^{*} \mathrm{~B}+\mathrm{CO}_{2}$ & $(36)$ & $4.0 \cdot 10^{14}$ & 88.3 & $2.9 \cdot 10^{9}$ \\
$\mathrm{~A} 3 \mathrm{~J}^{*} \mathrm{~B} \rightarrow \mathrm{A} 3 \mathrm{~J}$ & $(37)$ & $1.7 \cdot 10^{13}$ & 192.8 & $1.1 \cdot 10^{2}$ \\
\hline
\end{tabular}

surrogate molecule via the attack of $\mathrm{O}_{2}$ is several orders of magnitude lower and seems too small to make this step appear as the predominant channel for the degradation of the model molecule. An alternative activation reaction would be the $\mathrm{H}$-abstraction by radicals such as $\mathrm{O}, \mathrm{OH}$ or $\mathrm{OOH}$, see Table 3, reaction (2)-(4). The rate coefficient for e.g. the H-abstraction by $\mathrm{O}$ at $900 \mathrm{~K}$ is $k_{(900 K)}^{(4)} \approx 4 \cdot 10^{8} \mathrm{~s}^{-1}$. A concentration of $\mathrm{O}$ about $2.5 \cdot 10^{-11} \mathrm{~mol} \mathrm{~cm}^{-3}$ results in a time scale for this reaction of about 100 seconds, which is comparable to the experimental time scales.

Figure 19 contains also the energy diagram for the attack of $\mathrm{O}_{2}$ on the pyrenyl radical, A4J $+\mathrm{O}_{2} \rightarrow$ A4OOJ, reaction (5). which constitutes another possibility of activation. The rate coefficient for this reaction at $900 \mathrm{~K}$ is $k_{(900 K)}^{(5)} \approx 7 \cdot 10^{1} \mathrm{~cm}^{3} \mathrm{~mol}^{-1} \mathrm{~s}^{-1}$ and assuming constant $\mathrm{O}_{2}$ concentration of $5 \%$ vol this results in $k_{(900 K)}^{(5)} \approx 5 \cdot 10^{-5} \mathrm{~s}^{-1}$, which is is several orders of magnitude larger than $k_{(900 K)}^{(1)}$. Depending on the history of soot during formation or finishing treatment, soot contains radical sites in variable density in the graphene-like structures (Yamanaka et al. 2005). Compared with the model molecule A4, where just one radical site A4J is viewed, graphene-like structures in soot primary particles contain multiple radical sites, so that the reaction rate of oxygen with radical sites in graphene-like structures in soot primary particles may be a multiple of the rate of reaction (5) resulting in reasonably smaller time scales. When lumping together the reaction rates of the three activation channels, reaction (1), reactions (2)-(4) and reaction (5), the resulting reaction rate comes close to the experimental ones.

The consecutive reaction of A4J with $\mathrm{O}_{2}$ leads to A4OOJ providing three parallel pathways to A4JDO + O (reaction path a), A4JYC2O2 (reaction bath b) and A4OJDO (reaction path c), see Fig. 19. This opens pathways to further degradation via A4JDO $+\mathrm{O}_{2}$ (a1), $\mathrm{A} 4 \mathrm{JDO}+\mathrm{O}(\mathrm{a} 2), \mathrm{A} 4 \mathrm{OJDO}$ and A4JYC2O2 (bc1). The energy diagrams for these reaction pathways are given in Figs. 20, 21, and 22. The respective reaction rate coefficients are contained in Table 3.

As can be seen in Fig. 20, the consecutive reactions in reaction path a1, reaction (9)-(13), end with the radical species A3J, which is a polycyclic radical with one ring less compared with A4J, and 2 molecules of $\mathrm{CO}$. The bottleneck reaction of this sequence is reaction (9), see rate coefficients listed in Table 3. Assuming again constant $\mathrm{O}_{2}$ concentration of $5 \% \mathrm{vol}$ the rate coefficient of this reaction is $k_{(900 K)}^{(9)} \approx 5 \cdot 10^{-5} \mathrm{~s}^{-1}$, which is by orders of magnitude larger than that of reaction (1). Assuming again multiple sites accessible for oxidation, the reaction sequence contributes considerably to the degradation of graphene-like structures.

The alternative pathways a2, reaction (14)-(21), see Fig. 21, and bc1 reaction (22)-(27), see Fig. 22, form the species A3CJ and CO. The corresponding rate coefficients of these reactions listed in Table 3 are also large compared with the rate coefficient of the primary activation reaction and illustrate a considerable contribution to the degradation of graphene-like structures. The species $\mathrm{A} 3 \mathrm{CJ}$ is further converted by the attack of $\mathrm{O}$ and $\mathrm{O}_{2}$ 


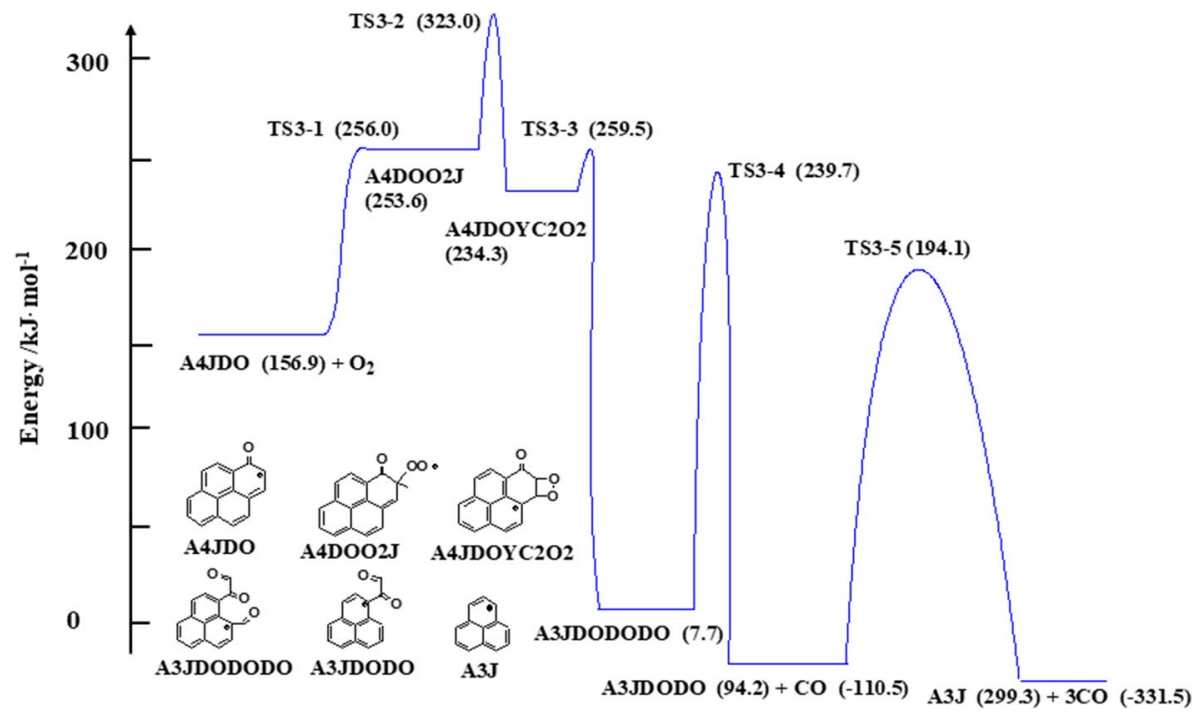

Fig. 20 Energy diagram for the follow-up reactions via reaction path a1; structures of the involved species are also indicated in the diagram

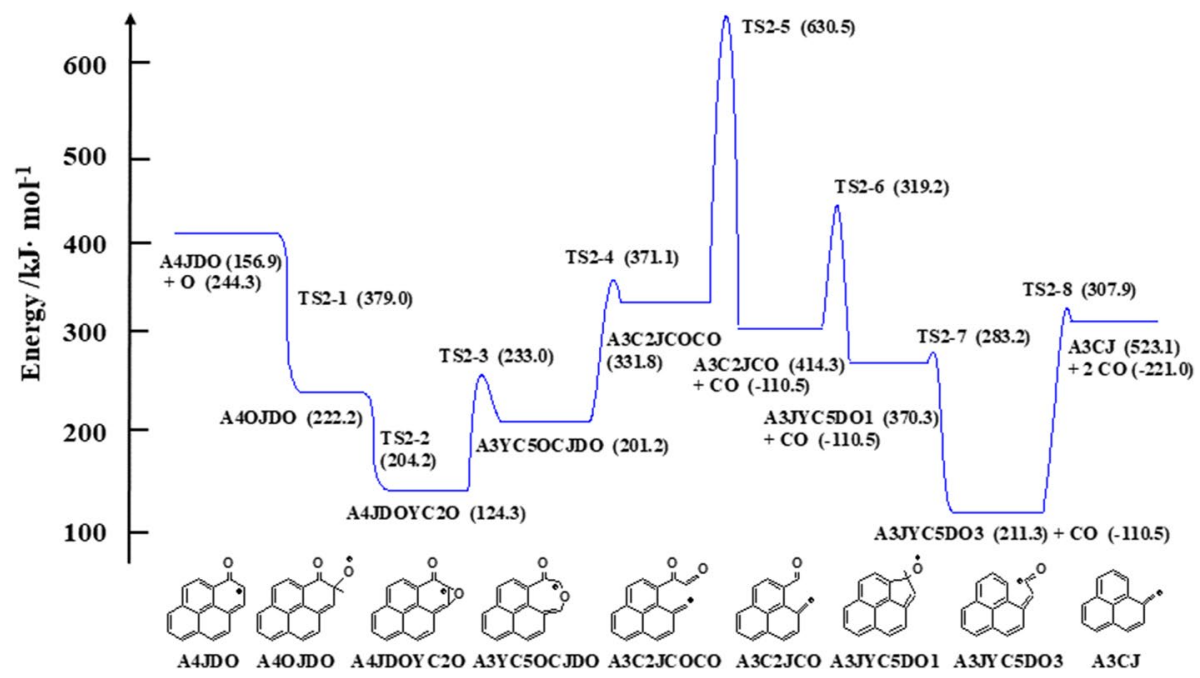

Fig. 21 Energy diagram for the follow-up reactions via reaction path a2; structures of the involved species are also indicated in the diagram

to $\mathrm{A} 3 \mathrm{~J}$ releasing $\mathrm{CO}$ and $\mathrm{CO}_{2}$ via reaction path bc11 and bc12. The corresponding energy diagrams are given in Fig. 23 and the rate coefficients are also contained in Table 3. The follow-up reactions via reaction path a,b,c and a1, a2 in combination with bc1 and bc11, bc12 form a replication reaction scheme leading to the degradation of one six-membered 


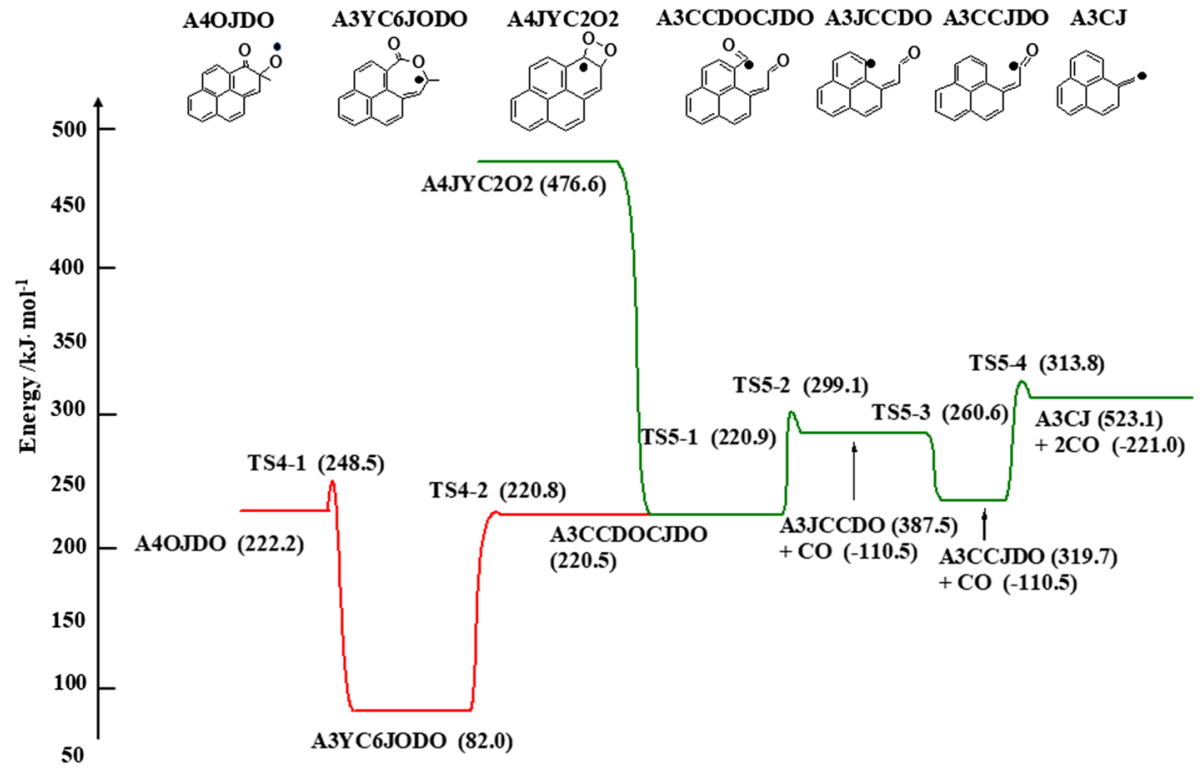

Fig. 22 Energy diagram for the follow-up reactions via reaction path bc1; structures of the involved species are also indicated in the diagram

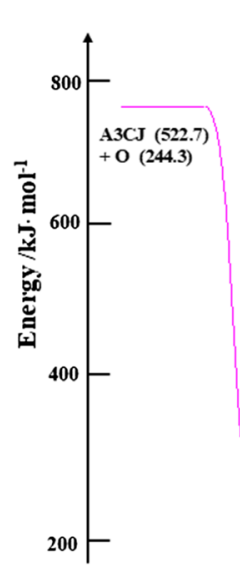

A3JCDO (181.2)

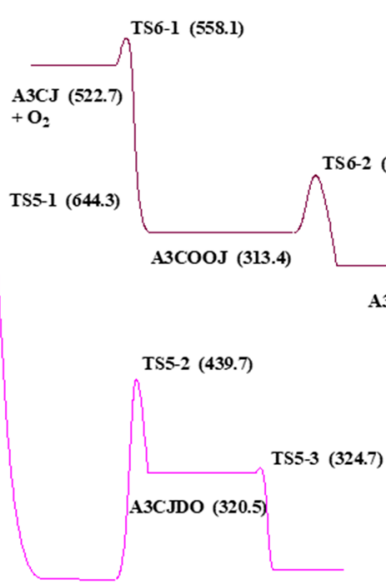

A3J (299.2) + CO (-110.5)

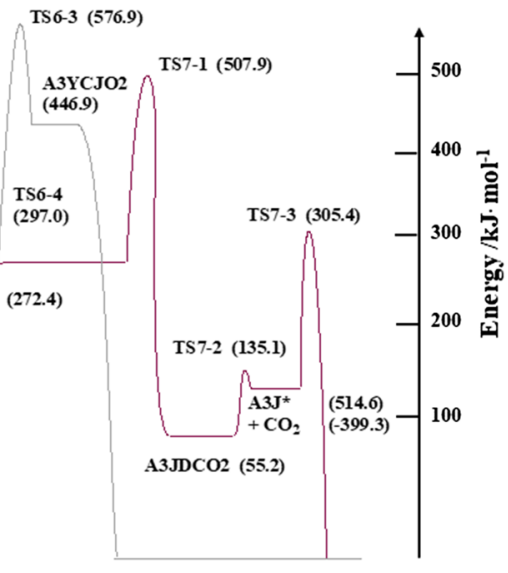

A3J (299.2) $+\mathrm{CO}_{2}(-399.3)$

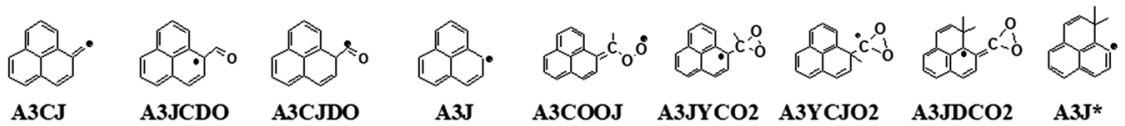

Fig. 23 Energy diagram for the follow-up reactions via reaction path bc11 and bc12; structures of the involved species are also indicated in the diagram 
ring after the other $(\mathrm{AnJ} \rightarrow \mathrm{A}(\mathrm{n}-1) \mathrm{J})$ releasing $\mathrm{CO}, \mathrm{CO}_{2}$ and also via reaction (6) oxygen atoms. In addition, the activation reaction (1) delivers $\mathrm{OOH}$, being together with $\mathrm{O}$ a potential candidate for activating aromatic ring systems via reaction (2) and (4) with a low energy barrier.

The discussion of the reaction paths presented here does not claim completeness. However, the developed activation/replication mechanism explains some experimental phenomena such as the increase in reactivity with increasing burn-out, the independent oxidation of differently reactive compartments in the soot or the increase in ordered structures at the expense of disordered/disturbed reactive structures, see Sect. 3.3. The primary attack of $\mathrm{O}_{2}$ at graphene-like layers via reaction (1) at temperatures in the range of $900 \mathrm{~K}$ contributes only little because of the high activation energy causing extremely low reaction rates. In contrast to this an alternative activation reaction via radicals such as $\mathrm{O}, \mathrm{OH}$ or $\mathrm{OOH}$ provides sufficiently high reaction rates at radical concentrations as low as $1 \cdot 10^{-11} \mathrm{~mol} \mathrm{~cm}^{-3}$. Reactions (1) and (6) in the sequence of follow up reactions delivers $\mathrm{OOH}$ and $\mathrm{O}$, so that the oxidation of graphene-like structures includes formation of activating species. Additionally, $\mathrm{O}, \mathrm{OH}$ and $\mathrm{OOH}$ may be produced via reactions in the gas phase. Another possibility of activation constitutes the reaction of $\mathrm{O}_{2}$ with radical $\mathrm{C}$-atoms requiring much lower activation energies, see reaction (5) in Table 3. The concentration of these "active" sites depends on the kind of soot and correlates with the method of synthesis. Flame generated soot and engine soot contain radical $\mathrm{C}$-atoms in different concentration (Yamanaka et al. 2005) than e.g. thermally aged soot (P25, AC100) and exhibit, therefore, different reactivity. Graphene-like structures in soot primary particles contain more edge active sites than the model molecule A4J, which can be attacked in parallel multiplying the degradation rate of these structures.

In summary, the mechanism given in Table 3 describes an activation/replicating mechanism AnJ $\rightarrow \mathrm{A}(\mathrm{n}-1) \mathrm{J}$ where the rates of the follow-up reactions are sufficiently high compared with the initial activation of the graphene-like structure by $\mathrm{O}_{2}$. The self-activation would explain the independent oxidation of different containments within the primary particles. The oxidation rate depends on the initial concentration of radical $\mathrm{C}$-atoms in the graphene-like structures in the soot and on the concentration of the radical pool of $\mathrm{O}, \mathrm{OH}$ and $\mathrm{OOH}$. Considering the different activation steps via the attack of $\mathrm{O}_{2}$ and radicals at $\mathrm{A} 4$ and the attack of $\mathrm{O}_{2}$ at $\mathrm{AJ}$ and their different reaction rates as discussed above, the experimental time scales for the oxidation can be reproduced with that replication/activation mechanism.

For deriving the reaction rate expression in Eq. 4 the density of "active" sites constituted by $\mathrm{C}-\mathrm{H}$-sites or radical sites was assumed to be proportional to the soot mass. For graphene-like structures, the ratio of edge $\mathrm{C}$ - $\mathrm{H}$-sites to total carbon atoms in the graphene-like layers increases with decreasing extension of the layers. The density af active sites, therefore, increases with decreasing size of the layers enhancing the reaction rates for reactions of type (1)-(5). Then the reactivity increases with decreasing extension of the graphenelike layers, which is the case for progressing oxidation of the primary soot particles. Also, the ratio of $\mathrm{C}$-H-sites to the total carbon atoms depends on the hydrogen content of the soot and generally a higher hydrogen content leads to higher reactivity (see Table 1). The same arguments hold for the degradation of graphene-like layers via the reaction of $\mathrm{O}_{2}$ with disordered/disturbed structures in the primary particles such as large graphene-like structures partially equipped with functional groups, aliphatic side chains and aliphatic bridges. The reactivity will be higher, the higher the relative concentration of distorted/reactive structures within the graphene-like layers. In addition, the stability of a graphene-like layer with or without radical/active site increases with its extension. An extended ring system facilitates the stabilization of the intermediate stage by conjugation (hyper-conjugation). 
Therefore, a distribution of activation energies for reactions (1)-(5) results depending on the stability of the activated graphene-like layers and thus on the layer extension. This supports again the findings of Sect. 3.3, that the reactivity increases with proceeding oxidation, viz. decreasing extension of the graphene-like layers.

While the investigation presented in this work identifies the predominant parameters determining the reactivity of "pure" soot the oxidation of soot in GPFs may be additionally affected by metals or metal oxides present in the emitted soot. This aspect opens the field of catalytic reactions of metal(oxides), which cannot be covered her. However, some principles developed in this work may be transferred also to catalytic oxidation, since recent studies show that initial graphene-like structures are shortened by adding catalytic additives (Rinkenburger et al. 2017).

\section{Conclusions}

The reactivity of soot from flames, soot from IC-engines, carbon blacks under oxidation conditions representative for GPF regeneration has been investigated. Soot reactivity is determined in dynamic TPO experiments and the soot primary particle nanostructure is investigated by HRTEM. Further, UV-visible spectroscopy and Raman scattering and other diagnostic techniques are used to study the properties connected to the reactivity of soot and to corroborate the experimental findings. It is found that nanostructural characteristics predominantly affect reactivity.

From the TPO experiments and the bulk properties of the soot samples no clear basic causes for the differences in reactivity of the different kinds of soot are obvious. Small soot primary particle sizes are not well correlated with high reactivity and also large specific surface area which correlates with small primary particle sizes causes different reactivity. Also the content of volatiles present in the different samples, the $\mathrm{C} / \mathrm{H}$-ratio and the oxygen content do not lead to comparable reactivity. Soot samples with alike bulk properties, e.g. P25, i-OCT1, A22 with a CMD of $\approx 30 \mathrm{~nm}$ or NGFG, C50_1200, C50_1600 with a BET of about $420 \mathrm{~m}^{2} \cdot \mathrm{g}^{-2}$ are unalike with respect to reactivity (widely varying $\mathrm{T}_{\max }$, temperature of maximum oxidation rate during TPO). Vice versa, soot samples with alike reactivity, e.g. P90, i-OCT3, P85, C50_1200 with $\mathrm{T}_{\max } \approx 940 \mathrm{~K}$ are unalike with respect to bulk properties such as CMD or BET.

In contrast to this, the nanostructural properties clearly affect the reactivity of the investigated soot samples. The distribution of fringe lengths and separation distances in the primary particles exhibit a clear correlation to reactivity. The smaller the fringe lengths and the wider the distribution of the fringe separation distance, the higher the reactivity. Small fringe lengths are connected to wide distributions of the separation distance and vice versa. The nanostructure of the soot primary particles essentially determines their reactivity against oxidation and a simple reactivity-nanostructure relation linearly correlates the mean length of the fringes in the primary particles with $\mathrm{T}_{\max }$, the temperature of maximum oxidation rate during TPO. UV-visible absorption spectra affirm qualitatively the structure-reactivity correlation.

The oxidation rates of soot samples with multiple $\mathrm{T}_{\max }$ can be reproduced by a linear combination of the oxidation rates of different soot samples with $\mathrm{T}_{\max }$ in the respective range. The conclusion from this behavior is that different compartments in the soot primary particles are oxidized independently governed by their reactivity. The extension of the fringe layers is the essential parameter describing the reactivity. Therefore, the 
nanostructure of soot primary particles containing different compartments with different reactivity can be composed also by a linear combination.

The reactivity of soot particles increases during oxidation. As the soot mass decreases due to oxidation the extension of the fringes decreases leading to an increase of reactivity according to the structure-reactivity correlation. This effect is more pronounced for the more reactive carbon blacks than for the less reactive ones. The size distribution of the primary particles hardly changes during stepwise oxidation suggesting an internal burning mode rather than a shrinking core mode under the employed conditions.

The mechanistic interpretation on the basis of quantum-chemistry estimations reveals a replication/activation mechanism which explains the experimental phenomena and the interpretation of reactivity on the basis of the nanostructural analyses.

Acknowledgements The authors are very grateful to the Deutsche Forschungsgemeinschaft for financial support within the project Partikelreaktivität (TR470/7-1, KO4830/2-1, SU249/6-1). Also, the authors would like to thank Prof. Dagmar Gerthsen and Dr. Heike Störmer from the Laboratory for Electron Microscopy (Karlsruhe Institute of Technology (KIT)) for everlasting help in preparing and interpreting electron microscopy images. Dr. Amin Velji, KIT deserves thanks for his constant support and willingness to discuss. The authors are obliged to Prof. Sven Kureti and Marlis Zimmermann from the Chair of Reaction Engineering at Technical University of Freiberg for preparing the Raman spectra of soot samples. Finally, the authors thank Dr. Puneet Verma from Queensland University of Technology for his help in the initial stages of development of the microstructure analysis code.

Funding Open Access funding provided by Project DEAL. This study was funded by Deutsche Forschungsgemeinschaft (Grant Numbers TR470/7-1, KO4830/2-1, SU249/6-1).

\section{Compliance with Ethical Standards}

Conflict of interest The authors declare that they have no conflict of interest.

Open Access This article is licensed under a Creative Commons Attribution 4.0 International License, which permits use, sharing, adaptation, distribution and reproduction in any medium or format, as long as you give appropriate credit to the original author(s) and the source, provide a link to the Creative Commons licence, and indicate if changes were made. The images or other third party material in this article are included in the article's Creative Commons licence, unless indicated otherwise in a credit line to the material. If material is not included in the article's Creative Commons licence and your intended use is not permitted by statutory regulation or exceeds the permitted use, you will need to obtain permission directly from the copyright holder. To view a copy of this licence, visit http://creativecommons.org/licenses/by/4.0/.

\section{References}

Aarna, I., Suuberg, M.E.: A review of the kinetics of the nitric oxide-carbon reaction. Fuel 76, 475-491 (1997)

Andino, J.M., Smith, J.N., Flagan, R.C., Goddard, W.A., Seinfield, J.H.: Mechanism of atmospheric photooxidation of aromatics: a theoretical study. J. Phys. Chem. 100, 10967-10980 (1996)

Apicella, B., Alfè, M., Barbella, R., Tregrossi, A., Ciajolo, A.: Aromatic strucutres of carbonaceous materials and soot inferred by spectroscopic analysis. Carbon 42, 1583-1589 (2004)

Bardi, M., Pilla, G., Gautrot, X.: Experimental assessment of the sources of regulated and unregulated nanoparticles in gasoline direct-injection engines. Int. J. Engine Res. 20, 128-140 (2019)

Becke, A.D.: A new mixing of Hartree-Fock and local density-functional theories. J. Chem. Phys. 98, 1372-1377 (1993)

Bhardwaj, O.P., Lüers, B., Holderbaum, B., Koerfer, T., Pischinger, S., Honkanen, M.: Utilization of HVO fuel properties in a high efficiency combustion system: part 2: relationship of soot characteristics with its oxidation behavior in DPF. SAE Int. J. Fuels Lubr. 7, 979-994 (2014) 
Botero, M.L., Chen, D., González-Calera, S., Jefferson, D., Kraft, M.: HRTEM evaluation of soot particles produced by the non-premixed combustion of liquid fuels. Carbon 96, 459-473 (2016)

Curtiss, L.A., Redfern, P.C., Raghavachari, K.: Gaussian-4 theory. J. Chem. Phys. 126, 084108-1-08410812 (2007)

Czerwinski, J., Comte, P., Engelmann, D., Heeb, N., Muñoz, M., Bonsack, P., Hensel, V., Mayer, A.: PNemission of gasoline cars MPI and potentials of GBF. SAE technical paper 2018-01-0363 (2018)

D'Anna, A.: Particle inception and grwoth: experimental evidences and a modelling attempt. In: Bockhorn, H., D’Anna, A., Sarofim, A.D., Wang, H. (eds.) Combustion Generated Fine Carbonaceous Particles, pp. 299-320. KIT Scientific Publishing, Karlsruhe (2009)

Durant, J.L.: Evaluation of transition state properties by density functional theory. Chem. Phys. Lett. 256, 595-602 (1996)

Edwards, D.E., You, X., Zubarev, D.Y., Lester, W.A., Frenklach, M.: Thermal decomposition of graphene armchair oxyradicals. Proc. Combust. Inst. 34, 1759-1766 (2013)

Edwards, D.E., Zubarev, D.Y., Lester, W.A., Frenklach, M.: Pathways to soot oxidation: reaction of $\mathrm{OH}$ with phenanthrene radicals. J. Phys. Chem. A 118, 8606-8613 (2014)

Fang, H L., Lance, J.: Influence of soot surface changes on DPF regeneration. SAE technical paper 2004-01-3043 (2004)

Ferrari, A.C., Robertson, J.: Interpretation of Raman spectra of disordered and amorphous carbon. Phys. Rev. B 61, 14095-14107 (2000)

Frenklach, M., Mebel, A.M.: On the mechanism of soot nucleation. Phys. Chem. Chem. Phys. 22, 53145331 (2020)

Frisch, M.J., Trucks, G.W., Schlegel, H.B., Scuseria, G.E., Robb, M.A., Cheeseman, J.R., Scalmani, G., Barone, V., Petersson, G.A., Nakatsuji, H., Li, X., Caricato, M., Marenich, A., Bloino, J., Janesko, B.G., Gomperts, R., Mennucci, B., Hratchian, H.P., Ortiz, J.V., Izmaylov, A.F., Sonnenberg, J.L., Williams-Young, D., Ding, F., Lipparini, F., Egidi, F., Goings, J., Peng, B., Petrone, A., Henderson, T., Ranasinghe, D., Zakrzewski, V.G., Gao, J., Rega, N., Zheng, G., Liang, W., Hada, M., Ehara, M., Toyota, K., Fukuda, R., Hasegawa, J., Ishida, M., Nakajima, T., Honda, Y., Kitao, O., Nakai, H., Vreven, T., Throssell, K., Montgomery Jr., J.A., Peralta, J.E., Ogliaro, F., Bearpark, M., Heyd, J.J., Brothers, E., Kudin, K.N., Staroverov, V.N., Keith, T., Kobayashi, R., Normand, J., Raghavachari, K., Rendell, A., Burant, J.C., Iyengar, S.S., Tomasi, J., Cossi, M., Millam, J.M., Klene, M., Adamo, C., Cammi, R., Ochterski, J., Martin, R.L., Morokuma, K., Farkas, O., Foresman, J.B., Fox, D.J.: Gaussian 09, Revision A.02. Gaussian, Inc., Wallingford (2016)

Galvez, A., Herlin-Boime, N., Reynaud, C., Clinard, C., Rouzaud, J.-N.: Carbon nanoparticles from laser pyrolysis. Carbon 40, 2775-2789 (2002)

Gonzalez, R.C., Woods, R.E.: Digital Image Processing. Prentice Hall, Upper Saddle River (2008)

Hagen, F., Rinkenburger, A., Günther, J., Bockhorn, H., Niessner, R., Suntz, R., Loukou, A., Trimis, D., Haisch, C.: Spark discharge-generated soot: varying nanostructure and reactivity against oxidation with molecular oxygen by synthesis conditions. J. Aerosol Sci. 143, 105530 (2020)

http://www.gaussian.com/index.htm

Huang, C.H., Vander Wal, R.L.: Partial premixing effects upon soot nanostructure. Combust. Flame 168, 403-408 (2016)

Jähne, B.: Digitale Bildverarbeitung. Springer, Berlin (2002)

Knauer, C., Carrara, M., Rothe, D., Niessner, R., Ivleva, N.P.: Changes in structure and reactivity of soot during oxidation and gasification by oxygen, studied by micro-Raman spectroscopy and temperature programmed oxidation. Aerosol Sci. Technol. 43, 1-8 (2009)

Koch, S., Hagen, F., Kubach, H., Velji, A., Koch, T., Bockhorn, H., Loukou, A., Suntz, R., Trimis, D.: Impact of the injection strategy on soot reactivity and particle properties of a GDI engine. SAE technical paper 2020-01-0392 (2020)

Köylü, Ü.Ö., Faeth, G.M., Farias, T.L., Carvalho, M.G.: Fractal and projected structure properties of soot aggragates. Combust. Flame 100, 621-633 (1995)

Lapuerta, M., Oliva, F., Agudelo, J.R., Boehman, A.L.: Effect of fuel on the soot nanostructure and consequences on loading and regeneration of diesel particulate filters. Combust. Flame 159, 844-853 (2012)

Lee, C., Yang, W., Parr, R.G.: Development of the Colle-Salvetti correlation-energy formula into a functional of the electron density. Phys. Rev. B 37, 785-789 (1988)

Lindner, S., Massner, A., Gärtner, U., Koch, T.: Impact of engine combustion on the reactivity of diesel soot from commercial vehicle engines. Int. J. Engine Res. 16, 104-111 (2014)

Lu, T., Cheung, C.S., Huang, Z.: Size-resolved volatility, morphology, nanostructure, and oxidation characteristics of diesel particulate. Energy Fuels 26, 6168-6176 (2012) 
Manion, J.A., Huie, R.E., Levin, R.D., Burgess, D.R. Jr., Orkin, V.L., Tsang, W., McGivern, W.S., Hudgens, J.W., Knyazev, V.D., Atkinson, D.B., Chai, E., Tereza, A.M., Lin, C.-Y., Allison, T.C., Mallard, W.G., Westley, F., Herron, J.T., Hampson, R.F., Frizzell, D.H.: NIST Chemical Kinetics Database. NIST Standard Reference Database 17, Version 7.0 (Web Version), Release 1.6.8, Data version 2015.09, National Institute of Standards and Technology, Gaithersburg (2015)

Mehl, M., Pitz, W.J., Westbrook, C.K., Curran, H.J.: Kinetic modeling of gasoline surrogate components and mixtures under engine conditions. Proc. Combust. Inst. 33, 193-200 (2011)

Montgomery, J.A., Ocherski, J.W., Petersson, G.A.: A complete basis set model chemistry. IV. An improved atomic pair natural orbital method. J. Chem. Phys. 101, 5900-5909 (1994)

Mühlbauer, W., Zöllner, C., Lehmann, S., Lorenz, S., Brüggemann, D.: Correlations between physicochemical properties of emitted diesel particulate matter and its reactivity. Combust. Flame 167, 39-51 (2016)

Neeft, J.P.A., Nijhuis, T.X., Smakman, E., Makkee, M., Moulijn, A.: Kinetics of the oxidation of diesel soot. Fuel 76, 1129-1136 (1997)

Palotas, A.B., Rainey, L.C., Feldermann, C.J., Sarofim, A.F., Vander Sande, J.B.: Soot morphology: an application of image analysis in high-resolution transmission electron microscopy. Microsc. Res. Tech. 33, 266-278 (1996)

Pawlyta, M., Rouzaud, J.N., Duber, S.: Raman microspectroscopy characterization of carbon blacks: spectral analysis and structural conformation. Carbon 84, 479-490 (2015)

Pfau, S.A., La Rocca, A., Haffner-Staton, E., Rance, G.A., Fay, M.W., Brough, R.J., Malizia, S.: Comparative nanonstructure analysis of gasoline turbocharged direct injection and diesel soot-in-oil with carbon black. Carbon 139, 342-352 (2018)

Reichert, D., Bockhorn, H., Kureti, S.: Study of the reaction of NOx and soot on $\mathrm{Fe}_{2 \mathrm{O}_{3}}$ catalyst in excess of $\mathrm{O}_{2}$. Appl. Catal. 80, 248-259 (2010)

Rinkenburger, A., Tiriyama, T., Yasuda, K., Niessner, R.: Catalytic effect of potassium compounds in soot oxidation. ChemCatChem 9, 3513-3525 (2017)

Sadezky, A., Muckenhuber, H., Grothe, H., Niessner, R., Pöschl, U.: Raman micro-spectroscopy of soot and related carbonaceous materials: spectral analysis and structural information. Carbon 43, 1731$1742(2005)$

Schäfer, T., Mauss, F., Bockhorn, H., Fetting, F.: Surface growth and oxidation of soot particles under flame conditions. Z. Naturforsch. 50a, 1009-1022 (1995)

Sebbar, N., Bockhorn, H., Bozzelli, J.W.: Thermochemical similarities among three reaction systems: Vinyl $+\mathrm{O}_{2}-$ Phenyl $+\mathrm{O}_{2}$ - Dibenzofuranyl $+\mathrm{O}_{2}$. Combust. Sci. Technol. 180, 959-974 (2008)

Sebbar, N., Bockhorn, H., Bozzelli, J.W.: Thermochemistry and reaction paths in the oxidation reaction of benzoyl radical: $\mathrm{C}_{6} \mathrm{H}_{5} \mathrm{C} \cdot(=\mathrm{O})$. J. Phys. Chem. A 115, 11897-11914 (2011)

Sebbar, N., Bockhorn, H., Bozzelli, J.W.: Kinetic study of di-tert-butyl peroxide: thermal decomposition and product reaction pathways. Int. J. Chem. Kinet. 47, 133-161 (2015)

Sediako, A.D., Soong, C., Howe, J.Y., Kholghy, M.R., Thomson, M.J.: Real-time observation of soot aggregate oxidation in an environmental transmission electron microscope. Proc. Combust. Inst. 36, 841-851 (2017)

Sendt, K., Haynes, B.S.: Density functional study of the reaction of $\mathrm{O}_{2}$ with a single site on the zigzag edge of graphene. Proc. Combust. Inst. 33, 1851-1858 (2011)

Serra, J.: Image Analysis and Mathematical Morphology. Academic Press, London (1989)

Sharma, A., Kyotani, T., Tomita, A.: A new quantitative approach for microstructural analysis of coal char using HRTEM images. Fuel 78, 1203-1212 (1999)

Sharma, A., Kyotani, T., Tomita, A.: Comparison of structural parameters of PF carbon from XRD and HRTEM techniques. Carbon 38, 1977-1984 (2000)

Shim, H.S., Hurt, R.H., Yang, N.Y.C.: A methodology for analysis of 002 lattice fringe images and its application to combustion-derived carbons. Carbon 38, 29-45 (2000)

Stanmore, B.R., Brilhac, J.F., Gilot, P.: The oxidation of soot: a review of experiments, mechanisms and models. Carbon 39, 2247-2268 (2001)

Su, D.S., Jentoft, R.E., Müller, J.-O., Rothe, D., Jacob, E., Simpson, C.D., Tomovic, Z., Müllen, K., Messerer, A., Pöschl, U., Niessner, R., Schlögl, R.: Microstructure and oxidation behaviour of Euro IV diesel engine soot: a comparative study with synthetic model soot substances. Catal. Today 90, 127-132 (2004)

The European Parliament and the Council of the European Union: Regulation (EC) No. 715/2007 of the European Parliament and of the Council. OJ L 171, pp. 1-16 (2007)

Toth, P., Palotas, A.B., Eddings, E.G., Whitaker, R.T., Lighty, J.A.L.: A novel framework for the quantitative analysis of high resolution transmission electron micrographs of soot I. Improved measurement of interlayer spacing. Combust. Flame 160, 909-919 (2013) 
Toth, P., Palotas, A.B., Ring, T.A., Eddings, E.G., Vander Wal, R.L., Lighty, J.A.S.: The effect of oxidation pressure on the equilibrium nanostructure of soot particles. Combust. Flame 162, 2422-2430 (2015)

Vander Wal, R.L., Tomasek, A.J.: Soot oxidation: dependence upon initial nanostructure. Combust. Flame 134, 1-9 (2003)

Vander Wal, R.L., Tomasek, A.J., Street, K., Hull, D.R., Thompson, W.K.: Carbon nanostructure examined by lattice fringe analysis of high-resolution transmission electron microscopy images. Appl. Spectrosc. 58, 230-237 (2004)

Vander Wal, R.L., Tomasek, A.J., Pamphlet, M.I., Taylor, C.D., Thompson, W.K.: Analysis of HRTEM images for carbon nanostructure quantification. J. Nanopart. Res. 6, 555-568 (2004)

Wan, K., Chen, D., Wang, H.: On imaging nascent soot by transmission electron microscopy. Combust. Flame 198, 260-266 (2018)

Yamanaka, C., Matsuda, T., Ikeya, M.: Electron spin resonance of particulate soot samples from automobiles to help environmental studies. Appl. Radiat. Isot. 62, 307-311 (2005)

Yehliu, K., Vander Wal, R.L., Boehman, A.L.: A comparison of soot nanostructure obtained using two high resolution transmission electron microscopy image analysis algorithms. Carbon 49, 42564268 (2011)

Yehliu, K., Vander Wal, R.L., Boehman, A.L.: Development of an HRTEM image analysis method to quantify carbon nanostructure. Combust. Flame 158, 1837-1851 (2011)

Zhang, H.-Y., McKinnon, J.T.: Elementyry reaction modeling of high-temperature benzene oxidation. Combust. Sci. Tech. 107, 261-300 (1995)

Zhang, T.Y., Suen, C.Y.: A fast parallel algorithm for thinning digital patterns. Commun. ACM 27, 236-239 (1984)

Zöllner, C., Brueggemann, D.: Optical and analytical studies on DPF soot properties and consequences for regeneration behavior. SAE technical paper 2017-24-0126 (2017)

\section{Affiliations}

\section{Fabian Hagen ${ }^{1} \cdot$ Fabian Hardock ${ }^{1} \cdot$ Sergej Koch ${ }^{2} \cdot$ Nadia Sebbar $^{1}$. Henning Bockhorn ${ }^{1} \cdot$ Alexandra Loukou ${ }^{1} \cdot$ Heiko Kubach $^{2} \cdot$ Rainer Suntz $^{3}$. Dimosthenis Trimis ${ }^{1} \cdot$ Thomas Koch $^{2}$}

Henning Bockhorn

henning.bockhorn@kit.edu

1 Division of Combustion Technology, Engler-Bunte-Institute, Karlsruhe Institute of Technology, Engler-Bunte-Ring 1, 76131 Karlsruhe, Germany

2 Institut für Kolbenmaschinen, Karlsruhe Institute of Technology, Rintheimer Querallee 2, 76131 Karlsruhe, Germany

3 Institute of Chemical Technology and Polymer Chemistry, Karlruhe Institute of Technology, Engesserstr. 18/20, 76131 Karlsruhe, Germany 